Research papers

\title{
Thermal discontinuities along a lowland river: The importance of urban areas and lakes
}

\author{
Roshni Arora ${ }^{\mathrm{a}, \mathrm{b}, \mathrm{c}, *}$, Marco Toffolon $^{\mathrm{c}}$, Klement Tockner ${ }^{\mathrm{a}, \mathrm{b}, \mathrm{d}}$, Markus Venohr ${ }^{\mathrm{a}}$ \\ ${ }^{a}$ Leibniz-Institute of Freshwater Ecology and Inland Fisheries, Müggelseedamm 310, 12587 Berlin, Germany \\ ${ }^{\mathrm{b}}$ Institute of Biology, Freie Universität Berlin, Takustrasse 3, 14195 Berlin, Germany \\ ${ }^{\mathrm{c}}$ Department of Civil, Environmental and Mechanical Engineering, University of Trento, via Mesiano 77, 38123 Trento, Italy \\ d Austrian Science Fund (FWF), Sensengasse 1, 1090 Vienna, Austria
}

\section{A R T I C L E I N F O}

This manuscript was handled by G. Syme

\section{Keywords:}

Stream temperature

Longitudinal heterogeneity

Land use

Urban

Lakes

Riparian

Heat budget

Air2stream model

\begin{abstract}
A B S T R A C T
Despite increasing knowledge on the spatio-temporal dynamics of river temperature, a master water quality variable, it remains a challenge to identify the landscape variables influencing thermal heterogeneity along entire river courses. The present study investigated the spatial heterogeneity of stream temperature (ST), and the role of landscape variables, at 20 locations along the $195 \mathrm{~km}$ course of the intensively managed lowland River Spree (NE Germany) over a period of nine months. Along the river, four distinct thermal sections were identified, created by thermal discontinuities induced by lakes and an urban area. Three approaches, namely heat budget modelling (estimating the unresolved residual heat flux), both in Eulerian and Lagrangian form, semi-empirical air2stream modelling, and statistical correlations were applied to quantify the observed thermal heterogeneity and the role of climatic (air temperature) and landscape variables (land use, lakes, stream azimuth). Urban areas and lakes were identified as heat sources (in summer), which induced ST discontinuities at different time scales (daily, monthly and during the entire study period). Statistical correlations showed that heat inputs and ST increased with increasing urban area and decreased with distance from lakes. Furthermore, comparison of observed STs and those simulated via the Lagrangian model revealed that heat advection was the dominant thermal process in a lake-influenced section and persisted over a distance of up to $20 \mathrm{~km}$. Simulations showed that this effect could not be significantly diminished even by complete riparian shading along the section, as the sub-daily ST reduced by an average of only $1.5^{\circ} \mathrm{C}$. Hence, plantation of riparian buffers should be complemented with additional mitigation measures such as improving the groundwater table recharge, managing the temperature of urban discharges, to mitigate climate change impacts on ST.
\end{abstract}

\section{Introduction}

In ecological systems, heterogeneity is defined as the 'complexity and variability in a system property in space and time' (Li and Reynolds, 1995). Natural heterogeneity in physical and chemical properties, such as water temperature, controls biodiversity and ecosystem processes along entire river courses (Vannote et al., 1980; Isaak and Rieman, 2013). Spatial heterogeneity and temporal variability in water temperature, which is a pivotal water quality variable (Webb, 1996; Friberg et al., 2009; Johnson et al., 2014), occur longitudinally, laterally and vertically in a river (Webb et al., 2008). Disruption in the natural thermal regime due to climate change, land use alteration, and modifications in river morphology and water flow affects the distribution and survival of aquatic organisms. For example, thermal refugia, which are thermal zones vital for many freshwater organisms during thermally unsuitable conditions, control the distribution of stenotherms (Poole and Berman, 2001).

During the past decades, rising river temperature trends have been documented worldwide (Kaushal et al., 2010; van Vliet et al., 2011; Isaak et al., 2012; Markovic et al., 2013; Rice and Jastram, 2015; Arora et al., 2016), and these trends will most likely continue in the near future (van Vliet et al., 2013). Although our understanding of the underlying mechanisms controlling thermal heterogeneity along rivers has progressed (Arscott et al., 2001; Brown and Hannah, 2008; Monk et al., 2013; Dugdale et al., 2015; Fullerton et al., 2015), major gaps remain (Webb et al., 2008; Hannah and Garner, 2015). For example, spatial heterogeneity of water temperature along medium and large rivers, and at intermediate scales (e.g. 10-100 km and greater), has received little attention so far (Fullerton et al., 2015, 2018). Also, thermal stress within such rivers, particularly those situated in the lowlands, due to

\footnotetext{
* Corresponding author at: Leibniz-Institute of Freshwater Ecology and Inland Fisheries, Justus-von-Liebig-Strasse 7, Adlershof, 12489 Berlin, Germany.

E-mail address: arora@igb-berlin.de (R. Arora).
} 


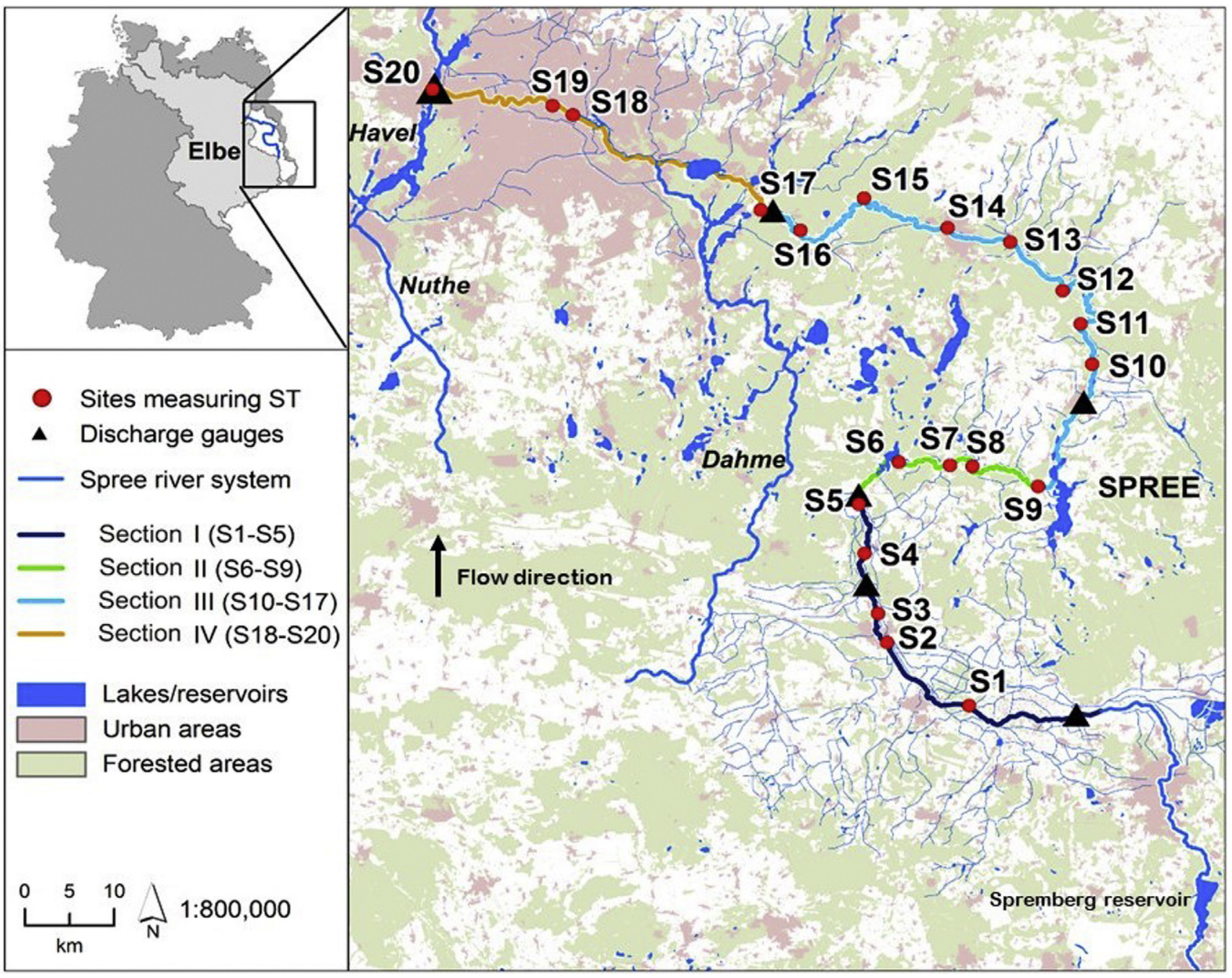

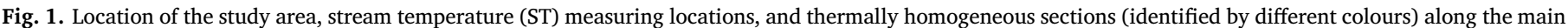

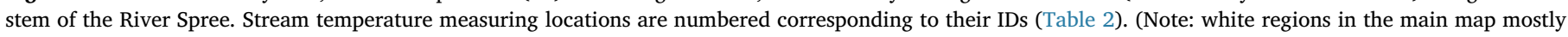
constitute of agricultural lands). (For interpretation of the references to colour in this figure legend, the reader is referred to the web version of this article.)

alteration of the thermal regime is a major concern and a key factor threatening freshwater ecosystem processes (Isaak and Rieman, 2013). Hence, quantifying and understanding spatial thermal heterogeneity, and its temporal variability, along river courses demands specific attention.

River temperature at a particular location and a specific date is a function of energy and hydrological fluxes at the interfaces between air, water and the streambed (Hannah and Garner, 2015). Hence, alterations in air temperature, flow, morphology and land use modify the energy fluxes and, therefore, influence thermal heterogeneity (Imholt et al., 2013; Hannah and Garner, 2015; Fullerton et al., 2015). While variation in climatic factors (air temperature, precipitation) and the hydrological regime (such as due to large reservoirs, e.g., Ellis and Jones, 2013; Cai et al., 2018) are responsible for large-scale patterns in water temperature, river morphology and land use primarily act at local scales. The influence of land use, particularly of riparian cover (see review by Moore et al. (2005); Malcolm et al. (2008) and urbanization (LeBlanc et al., 1997; Nelson and Palmer, 2007; Somers et al., 2013; Booth et al., 2014, Dugdale et al., 2018), on river temperature has been investigated widely. Indeed, there is clear evidence that the removal of the riparian vegetation and the presence of urban areas substantially increase local and regional river temperature (Moore et al., 2005; Somers et al., 2013). While riparian vegetation cover has been frequently used to determine river thermal heterogeneity (Pedersen and
Sand-Jensen, 2007; Hrachowitz et al., 2010; Broadmeadow et al., 2011; Mayer, 2012; Imholt et al., 2013; Hebert et al., 2011; Garner et al., 2014), few studies have investigated the role of urban and agricultural cover (Chang and Psaris, 2013; Sun et al., 2015). In some cases, forest cover was a better explanatory variable for river temperature heterogeneity than urban or agricultural cover (Chang and Psaris, 2013; Sun et al., 2015). In other cases, higher river temperature warming rates and sensitivities were observed due to the presence of urban areas (Kaushal et al., 2010; Kelleher et al., 2012; Rice and Jastram, 2015).

Along rivers, the influence of land use on thermal heterogeneity has been studied at large scales (Booth et al., 2014), or among systems that differ in land use (Nelson and Palmer, 2007; Somers et al., 2013). To our knowledge, no study has yet quantified the effects of different land use types on thermal heterogeneity along an entire river course. We expect that local land use types (e.g., forest, urban, agricultural areas) alter thermal patterns along rivers (i.e., longitudinal heterogeneity), similar to what has been observed for air temperatures (urban heat island profile, EPA (2008)). Hence, in the present study, we quantified the spatial heterogeneity of water temperature and its temporal variability along a $\sim 200 \mathrm{~km}$ lowland river (River Spree, NE Germany), which traverses a mosaic of forested, agricultural and urban areas, as well as shallow natural lakes and weirs. Specifically, we addressed the following questions: 
1) How does stream temperature (ST) vary along the river course, and are there distinct thermal discontinuities (i.e. abrupt changes) defining longitudinal heterogeneity?

2) Are riparian forest, urban and agricultural buffer widths critical in inducing thermal discontinuities along the river course? At which temporal scales (daily, monthly, entire study period) are the effects of land use on thermal heterogeneity most evident?

3) How do lakes and geographic orientation (i.e. azimuth) of a river reach affect thermal heterogeneity?

4) Can approaches such as heat budget modelling, semi-empirical modelling and statistical analyses appropriately quantify and explain thermal discontinuities?

5) How is air temperature, a major explanatory climatic variable, related to stream temperature along a river course? Are statistical models (i.e., linear and logistic regressions) more efficient than a semi-empirical model (air2stream; Toffolon and Piccolroaz, 2015) in capturing air-stream temperature relationships?

\section{Material and methods}

\subsection{Study area}

The River Spree is a sixth-order lowland river (catchment area: $10,100 \mathrm{~km}^{2}$ ), located in the Elbe catchment in north-eastern Germany. It originates at $390 \mathrm{~m}$ above sea level (asl) in the Lusatian Mountains near the Czech border. Along its $380 \mathrm{~km}$, the River Spree traverses several shallow lakes and man-made reservoirs before entering the River Havel, a main tributary of the Elbe River, at $30 \mathrm{~m}$ asl in Berlin. For this study, the $\sim 200 \mathrm{~km}$ long lower course of the River Spree, between Leipe (Brandenburg) and Spandau (Berlin), was sampled (Fig. 1). The lower course of the river flows through the Glogów-Baruth glacial valley. Here, the river changes its direction several times, as it follows glacial valleys or is guided by the arrangement of sandurs and glacial ground moraines. The average slope ranges between 0.001 and $0.13 \%$ (Kozerski et al., 1991). In 2014, mean annual discharge was $4 \mathrm{~m}^{3} \mathrm{~s}^{-1}$ at Fehrow and $23 \mathrm{~m}^{3} \mathrm{~s}^{-1}$ at Spandau. Between Cottbus and Berlin, the specific runoff ranged from 2.4 to $4.1 \mathrm{~L} \mathrm{~km}^{-2} \mathrm{~s}^{-1}$ (1997-2007; Pusch et al., 2009). The seasonal flow regime is regulated and dampened by the presence of reservoirs (upstream of the study area) and managed lake outlets (Kozerski et al., 1991).

The lower Spree catchment exhibits a sub-continental climate, with cold winters and hot and dry summers. The average annual air temperature at Lindenberg, located in the center of the lower catchment, was $9.2^{\circ} \mathrm{C}\left(1981-2010\right.$; winter $=0.4^{\circ} \mathrm{C}$, summer $\left.=18^{\circ} \mathrm{C}\right)$. It is one of the driest regions in Germany (average annual precipitation at Lindenberg: $480 \mathrm{~mm}$; 1981-2010). Upstream of Berlin, the lower Spree catchment is covered by forests (41.5\%), cropland (43.4\%), settlements (4.6\%), and surface waters (2.2\%) (Pusch et al., 2009).

The lowland Spree is intensively managed for drinking water supply, recreation, cooling of power plants, as a receiver of tertiarytreated wastewater and a waterway for navigation. At the same time, the River Spree has undergone severe transformations due to open-cast lignite mining in the past, making it one of the most intensively managed rivers globally (Pusch et al., 2009).

\subsection{Dataset}

From 1 January 2014 to 31 December 2014, stream temperature (ST) was recorded at $15 \mathrm{~min}$ intervals at 20 locations along the lowland course of the River Spree (Fig. 1). The ST was recorded using Gemini TinyTagPlus data loggers (model TG-4100) with an internal encapsulated thermistor. The stated precision of the loggers is $\pm 0.2^{\circ} \mathrm{C}$. The loggers were cross-calibrated prior to installation. Temperature differences among loggers were $\pm 0.1{ }^{\circ} \mathrm{C}$. Due to dewatering events and delays in data downloading, only 13 out of the 20 loggers had data available for the entire year. Therefore, for correlation and regression analyses, the data until 15 September 2014 (i.e., data available for all sites) were considered, whereas the whole data set was used for model applications. As we did not have observational data for the complete year, proper segregation of data into four seasons was not possible. Hence, the winter and spring months were taken broadly as winter (Jan-May), while the summer and autumn months were considered as summer (Jun-Sep).

Hourly data for climatological variables including air temperature and relative humidity (five stations), wind velocity, atmospheric pressure, cloud cover and shortwave radiation (one station) were downloaded from the Deutsche Wetter Dienst (DWD, www.dwd.de) for the relevant period. The daily air temperature in the study region ranged from -11.4 to $27.6^{\circ} \mathrm{C}$, a representative year in terms of air temperature between 2004 and 2014 (Fig. S1). The data of the five meteorological stations were averaged for each time step to obtain air temperature and relative humidity data for the entire region. This was done primarily to ensure same climatic forcing on the river course such that the land-use induced differences in the climate, and thereby ST, were captured by the model terms and also to eliminate the influence of the distance between the station and the river. Daily discharge data (six stations, Fig. 1) were obtained from the Landesamt für Umwelt, Gesundheit und Verbraucherschutz (LUGV; www.luis.brandenburg.de/).

A total of 14 relevant landscape variables were included in the analyses: Shares (\%) of land use types for different riparian buffer strip widths, river network distance of sites from the closest lake (lake distance), and stream azimuth (Table 1; Fig. 1, Fig. S2). Land use data were obtained from the ATKIS land use dataset (resolution: $10 \mathrm{~m} \times 10 \mathrm{~m}$; ADV, 2012, Germany). Lake distances and stream azimuth values were calculated from Google Earth. Azimuth was measured as the clockwise angle (in degrees) that the longitudinal dimension of the river reach differed from due south (e.g., from the south $=0^{\circ}$, west $=+90^{\circ}$, east $=-90^{\circ}$ ) (Arscott et al., 2001). Since the elevation (30-58 $\mathrm{m})$ and river width (18-50 $\mathrm{m}$, except in the last stretch) varied little along the studied river course, these variables were not considered in present analyses.

\subsection{Quantification of landscape contributions to thermal heterogeneity, the air-water temperature relationship and dominant thermal processes}

This section elaborates on the models used to quantify the thermal heterogeneity. A combination of physically based models (heat-budget model, Lagrangian model), semi-empirical (air2stream) and statistical models (regression, correlations) were used to quantify the thermal discontinuities and the responsible factors. The heat budget, semi-empirical and statistical models were applied for each river reach, which were defined by the ST measuring site locations. The Lagrangian model was specifically used to identify the dominant thermal processes along a particular section (Section II, S6-S9) of the river.

\subsubsection{Physically based models}

2.3.1.1. Heat budget model (HB). Heat content variations in a river

Table 1

Hydro-climatological and landscape variables considered in the analysis.

\begin{tabular}{ll}
\hline Hydro-climatological variables & Landscape variables \\
\hline Air temperature $\left[{ }^{\circ} \mathrm{C}\right]$ & Forest area (F_) in $50 \mathrm{~m}, 100 \mathrm{~m}, 500 \mathrm{~m}, 1000 \mathrm{~m}$ \\
& buffers (\%) \\
Agricultural area (A_) in $50 \mathrm{~m}, 100 \mathrm{~m}, 500 \mathrm{~m}$, \\
Solar radiation $\left[\mathrm{J} \mathrm{cm}^{-2}\right]$ & $1000 \mathrm{~m}$ buffers (\%) \\
& Urban area (U_) in $50 \mathrm{~m}, 100 \mathrm{~m}, 500 \mathrm{~m}, 1000 \mathrm{~m}$ \\
Relative humidity [\%] & buffers (\%) \\
& Lake distance [m] \\
Wind velocity [m s$\left.{ }^{-1}\right]$ & Stream azimuth $\left[{ }^{\circ}\right]$ \\
Atmospheric pressure $[\mathrm{mbar}]$ & \\
Cloud cover [okta] & \\
Discharge $\left[\mathrm{m} \mathrm{s}^{-3}\right]$ &
\end{tabular}


reach was computed using the following energy balance:

$\frac{d}{d t}\left(\rho C_{p} V T_{w}\right)=H_{u p}-H_{\text {down }}+S\left(E_{\text {atm }}+E_{r}+\Delta E\right)$

where $T_{w}$ is the ST, $\rho$ is the density (assumed constant, $997 \mathrm{~kg} \mathrm{~m}^{-3}$ ), $C_{p}$ is the specific heat of water (assumed constant, $4179 \mathrm{~J} \mathrm{~kg}^{-1}{ }^{\circ} \mathrm{C}^{-1}$ ), $V$ is the reach volume $\left(\mathrm{m}^{3}\right), S$ is the surface area $\left(\mathrm{m}^{2}\right), H_{u p}$ is the total heat flux (W) entering the upstream portion of a reach, $H_{\text {down }}$ is the total heat flux (W) exiting downstream, and $E_{\text {atm }}$ is the net atmospheric exchange per unit surface $\left(\mathrm{W} \mathrm{m}^{-2}\right)$. The various heat flux components of $E_{\text {atm }}$ (solar radiation, sensible and latent heat flux, evaporation, condensation, etc.) were calculated using the relationships reported in Martin and McCutcheon (1998) (see Appendix I). All the coefficients that are independent of ST were estimated as an average value for the whole study area. The value $\Delta E$ is a correction factor $\left(\mathrm{W} \mathrm{m}^{-2}\right)$ accounting for global uncertainties in the determination of $E_{\text {atm }}$. It was essentially the difference in the net atmospheric exchange values estimated as a function of the rate of change in ST (left hand side term in Eq. (1) divided by $S$ ) and via empirical heat budget equations (Eq. (1) in Appendix I), using spatially averaged ST (mean across all sites at daily time step) as input. Finally, $E_{r}$, the remaining energy flux term $\left(\mathrm{W} \mathrm{m}^{-2}\right)$, was expected to be a contribution of unresolved nonatmospheric sources not included in $H_{u p}$ such as land use-based sources (wastewater, urban outflows), inflows from lakes, tributaries and groundwater. It was calculated referring to each reach rescaled by the surface area $S$ and is site-specific. Since the solar radiation values were region-based and not site-specific, effects of incident solar radiation in shaded areas (reduced heat inputs as compared to open areas) are also included in $E_{r}$.

Eq. (1) was applied to each computational river reach which had a discrete ST, $T_{w, i}^{k}\left({ }^{\circ} \mathrm{C}\right.$, with $i$ the index for space and $k$ for time) in the volume $V_{i}$. Assuming steady hydraulic conditions (i.e., constant discharge, $Q\left(\mathrm{~m}^{3} \mathrm{~s}^{-1}\right)$, and cross-section) and complete mixing along a computational reach $i$ (downstream temperature $T_{w, \text { down }} \cong T_{w, i}^{k}$ ), the upstream and downstream heat fluxes were calculated as $H_{u p}=\rho C_{p} Q_{i} T_{w, i-1}$ and $H_{\text {down }}=\rho C_{p} Q_{i} T_{w, i}$, respectively. Thus, the heat budget Eq. (1) was discretized as

$\frac{T_{w, i}^{k+1}-T_{w, i}^{k}}{\Delta t}=\frac{Q_{i}}{V_{i}}\left(T_{w, i-1}^{k}-T_{w, i}^{k}\right)+S_{i} \frac{E_{a t m}+\Delta E}{\rho C_{p} V_{i}}+S_{i} \frac{E_{r, i}}{\rho C_{p} V_{i}}$

The volume was estimated as $V_{i}=B_{i} D_{i} L_{i}$, where $B_{i}$ is the river width (m), $D_{i}$ is the average depth (m) and $L_{i}$ the length (m) of the reach (values based on limited cross-section data). All the surface heat fluxes were calculated referring to a surface area $S_{i}=B_{i} L_{i}$. Assuming that the ST changes across space and time are known, Eq. (2) yields a way to estimate the residual heat term,

$E_{r, i}=\rho C_{p} D_{i}\left(\frac{T_{w, i}^{k+1}-T_{w, i}^{k}}{\Delta t}\right)-\rho C_{p} \frac{Q_{i}}{B_{i} L_{i}}\left(T_{w, i-1}^{k}-T_{w, i}^{k}\right)-E_{a t m}-\Delta E$

Some assumptions were used to derive a meaningful interpretation of the residual term $E_{r}\left(\mathrm{~W} \mathrm{~m}^{-2}\right)$. Groundwater-related spatial differences in ST were assumed to be negligible because water conductivity, an indicator of groundwater inflow (Johnson and Wilby, 2015), was similar at most of the sites (Table 2). Tributary contributions were not considered as discharge data on small streams/canals flowing into River Spree were not available and no major tributary confluences exist along the study reach (except River Dahme, which joins River Spree in its final reach). Ultimately, $E_{r}$ was assumed to mainly consist of heat contributions from land use sources and lake outflows within the reach.

For this analysis, since the discharge information was available at only six stations, the information from the station closest to each reach was used (Fig. 1, Table S1). The calculations were performed using daily averaged values of ST and hydro-climatological variables.

2.3.1.2. Lagrangian model. To understand how upstream conditions, particularly presence of lakes, influence downstream ST, we developed and applied a simple Lagrangian model (e.g., Leach and Moore, 2011) to a single section within the study area. For this exercise, the ST was simulated at the downstream site (S9) of the river section bounded by sites S6 and S9, as the upstream site S6 is located at a lake outlet. This particular river section was chosen because it was the only section where the heat inputs were solely due to one heat source (a lake and not also an urban area). The simulation was performed for a period of 27 days in July (5/07-31/07), the hottest period of the year, when the entire study area, including the lake, receives the maximum amount of heat via solar radiation.

The Lagrangian model (LAGR) is based on the heat budget approach described in the Section 2.3.1.1. The reach was divided into a series of sub-reaches bounded by nodes (index $j$ ), and a water parcel having an initial ST (based on measured values) was released from the upstream boundary at each time step. As the water parcel flows downstream from one node to the next $(j$ to $j+1)$, the model computed the heat inputs and the consequent change in ST over the stream sub-reach. This is represented as follows:

$T_{w}\left(x_{j+1}, t_{k+1}\right)=T_{w}\left(x_{j}, t_{k}\right)+\left(\rho C_{p} D_{j}\right)^{-1} \sum E_{l} \Delta t$

where $\sum E_{l}=E_{a t m}+E_{r}+\Delta E$ represents the sum of all the external heat fluxes acting in the time interval $\Delta t=t_{k+1}-t_{k}(15 \mathrm{~min})$ on the water parcel that is transported from $x_{j}$ to $x_{j+1}=x_{j}+U_{j} \Delta t$.

In our simulation, the flow velocity $U_{j}$ was assumed as constant in each sub-reach $L_{i}$. For this analysis, reference values of flow velocity $=U 0.2 \mathrm{~m} / \mathrm{s}$ and depth $=D 1 \mathrm{~m}$ were estimated as a first approximation. For this, uniform flow conditions were assumed in rectangular cross-sections having width $=B 40 \mathrm{~m}$, as the information on the longitudinal variation of the cross-sections of the reach was insufficient.

In order to highlight the role of advective heat fluxes on ST, we also tested the performance of a version of the Eulerian model based only on local heat exchanges (we term this model as "local" [LOC]), applied at each site $i$. This model is not physically realistic because it neglects the terms $H_{u p}$ and $H_{\text {down }}$ in Eq. (1), but was designed to disentangle the local effect from the advective transport. Thus, Eq. (2) reads

$T_{w}\left(x_{i}, t_{k+1}\right)=T_{w}\left(x_{i}, t_{k}\right)+\left(\rho C_{p} D_{j}\right)^{-1} \sum E_{l} \Delta t$

where the ST changes are driven only by the local atmospheric exchange term $\sum E_{l}$. The resulting ST values were compared with those obtained from the LAGR model. Additionally, the role of riparian buffer in regulating ST was also determined in the same river Section S6-S9. To do this, STs were simulated under a completely shaded scenario (zero incident solar radiation input) and compared with the STs simulated under current conditions ( $70 \%$ solar radiation), using both models (Eqs. (4) and (5). This would give insight on the efficacy of riparian buffering on sections including and excluding the effects of advection.

\subsubsection{Hybrid semi-empirical model}

Statistical models might not be the best option to describe and predict ST, especially at fine spatial (Arismendi et al., 2014) and time scales (Piccolroaz et al., 2016). With the aim to evaluate models other than statistical models but of similar complexity, an alternative approach was applied to relate ST to air temperature. The air2stream model (Toffolon and Piccolroaz, 2015) represents an adaptation (for rivers) of the air2water approach that was successfully applied to predict lake surface temperature as a function of air temperature (Piccolroaz et al., 2013, 2015, 2018; Toffolon et al., 2014). It is based on a lumped heat budget approach that considers an unknown volume of the river reach, its tributaries (implicitly considering both surface and subsurface water fluxes), and the heat exchange with the atmosphere. The heat budget equation (simplified from Eq. (1)) only considers air temperature, taken as a proxy of the other processes (see Toffolon and Piccolroaz, 2015 for further details). As discharge data were not available for all ST sites, the 5-parameter version of the model, 
Table 2

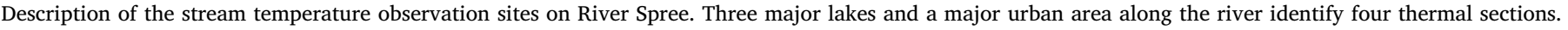

\begin{tabular}{|c|c|c|c|c|c|c|c|c|c|c|}
\hline $\begin{array}{l}\text { Thermally } \\
\text { different } \\
\text { sections }\end{array}$ & Site ID & Name & Distance $(\mathrm{km})$ & $\begin{array}{l}\text { Mean ST } \\
\text { for entire } \\
\text { period }\end{array}$ & $\begin{array}{l}\text { Maximum ST } \\
\text { (sub-daily; } \\
15 \mathrm{~min} \text { ) }\end{array}$ & $\begin{array}{l}\text { Time at } \\
\text { maximum ST }\end{array}$ & $\begin{array}{l}\text { Forest Area } \\
\text { (\% of total in } \\
\text { the reach; } \\
50 \text { m wide } \\
\text { buffer) }\end{array}$ & $\begin{array}{l}\text { Urban Area } \\
\text { (\% of total in } \\
\text { the reach; } \\
50 \text { m wide } \\
\text { buffer) }\end{array}$ & $\begin{array}{l}\text { Distance from } \\
\text { the closest } \\
\text { lake }(\mathrm{km})\end{array}$ & $\begin{array}{l}\text { Conductivity ( } \mu S \\
\mathrm{~cm}^{-1} \text {; based on daily } \\
\text { mean value on } 14 \text { Jan } \\
2008 \text { ) }\end{array}$ \\
\hline \multirow[t]{5}{*}{ Section I } & $\mathrm{S} 1$ & Leipe & 0 & 13.04 & 24.25 & $21-07$ 17:15 & 30 & 16 & 51 & 947 \\
\hline & S2 & Lubben & 14 & 13.06 & 24.87 & $21-0717: 30$ & 62 & 17 & 65 & 857 \\
\hline & S3 & Hartmannsdorf & 18 & 13.14 & 25.26 & $21-07$ 17:00 & 32 & 50 & 69 & 822 \\
\hline & S4 & Schlepzig & 27 & 13.25 & 25.30 & $22-07$ 18:00 & 92 & 2 & 78 & NA \\
\hline & S5 & Leibsch & 33 & 13.32 & 25.26 & $22-07$ 18:15 & 33 & 5 & 84 & 815 \\
\hline \multicolumn{11}{|c|}{ Neuendorfer See (surface: $3.3 \mathrm{~km}^{2}$; max depth: $4.5 \mathrm{~m}$ ) } \\
\hline \multirow[t]{4}{*}{ Section II } & S6 & Altschadow & 42 & 13.95 & 27.78 & $20-07$ 15:00 & 13 & 10 & 0.5 & 893 \\
\hline & S7 & Werder & 49 & 13.90 & 26.83 & 21-07 02:15 & 19 & 1 & 8 & NA \\
\hline & S8 & Kosenblatt & 52 & 13.73 & 27.08 & $21-07$ 15:00 & 23 & 6 & 11 & NA \\
\hline & S9 & Trebatsch & 62 & 13.77 & 26.37 & 21-07 23:15 & 22 & 7 & 21 & 0.88 \\
\hline \multicolumn{11}{|c|}{ Glower See (surface: $1.2 \mathrm{~km}^{2}$; max depth: $3.6 \mathrm{~m}$ ) } \\
\hline \multirow[t]{8}{*}{ Section III } & $\mathrm{S} 10$ & Radinkendorf & 81 & 14.13 & 26.88 & $21-07$ 16:15 & 41 & 13 & 2 & 823 \\
\hline & S11 & Rassmansdorf & 87 & 14.03 & 26.41 & $21-07$ 16:30 & 25 & 2 & 8 & 0.84 \\
\hline & S12 & Drahendorf & 99 & 13.80 & 25.77 & $20-07$ 16:15 & 35 & 3 & 10 & 837 \\
\hline & $\mathrm{S} 13$ & Berkenbrucke & 108 & 13.84 & 26.59 & $22-0711: 30$ & 52 & 5 & 19 & NA \\
\hline & S14 & Furstenwalde & 116 & 13.97 & 26.79 & $20-07$ 15:00 & 35 & 65 & 27 & 836 \\
\hline & S15 & Hangelsberg & 129 & 13.73 & 26.34 & $22-07$ 13:15 & 38 & 7 & 40 & NA \\
\hline & S16 & Freienbrink & 141 & 13.81 & 26.42 & 20-07 19:00 & 21 & 3 & 52 & NA \\
\hline & S17 & Neu zittau & 148 & 13.24 & 24.79 & 20-07 18:00 & 15 & 9 & 59 & 832 \\
\hline \multicolumn{11}{|c|}{ Müggelsee (surface: $7.7 \mathrm{~km}^{2}$; max depth: $8 \mathrm{~m}$ ); enters Berlin city } \\
\hline \multirow[t]{3}{*}{ Section IV } & S18 & Warschauer str & 176 & 14.14 & 26.59 & $20-07$ 18:00 & 33 & 53 & 16 & NA \\
\hline & S19 & Jannowitz & 179 & 14.18 & 26.63 & $20-07$ 15:00 & 0 & 100 & 19 & 824 \\
\hline & $\mathrm{S} 20$ & Spandau & 195 & 14.52 & 26.61 & $20-07$ 14:45 & 7 & 93 & 35 & 835 \\
\hline
\end{tabular}

which does not need this information, was used for this analysis:

$\frac{d T_{w}}{d t}=a_{1}+a_{2} T_{a}-a_{3} T_{w}+a_{4} \cos \left[2 \pi\left(\frac{t}{t_{y}}-a_{5}\right)\right]$

where $T_{a}$ is the air temperature $\left({ }^{\circ} \mathrm{C}\right), t$ is time (days), $t_{y}$ is the duration of a year (days) and $a_{1}-a_{5}$ are constant parameters. The values of these parameters are estimated through calibration, so that neither the geometrical characteristics of the reach (length, volume, area, etc.) nor the roles of specific heat inputs (e.g., along-reach inflows) are explicitly specified. The term $a_{2} T_{a}$ in Eq. (6) represents the effect of air temperature (i.e., processes associated with exchanges with the atmosphere) on the net heat flux. The last term on the right hand side of Eq. (6) accounts for the heat fluxes associated with inflows and the contribution of factors (such as groundwater, land use, lakes), which modify ST dynamics but are of difficult determination. Parameter $a_{5} \in$ $[0,1]$ is the phase of this additional term (Table S2), which normally peaks in summer, and is calibrated together with the other parameters (Toffolon and Piccolroaz, 2015). Given the short ST record in the present study (January-December 2014; including data gaps), the parameters of Eq. (6) were calibrated using the entire dataset.

If we divide Eq. (6) with the coefficient of $T_{w}, a_{3}$, we obtain

$C_{3} \frac{d T_{w}}{d t}=C_{1}+C_{2} T_{a}-T_{w}+C_{4} \cos \left[2 \pi\left(\frac{t}{t_{y}}-a_{5}\right)\right]$

where $C_{3}=1 / a_{3}$, and $C_{n}=a_{n} / a_{3}(n=1,2,4)$. Parameter $C_{3}$ is a measure of the time scale for adaptation of ST to local conditions (very small values implies instantaneous adaptation) and values of $C_{3}$ shorter than the time scale of the data (daily, in this case) would imply the possibility to obtain the equilibrium temperature at each time step (Toffolon and Piccolroaz, 2015). Parameters $C_{2}$ and $C_{4}$ are the measures of sensitivity to air temperature and contribution of seasonally varying heat inputs from sources that are not explicitly resolved (e.g., solar radiation, heated effluents from urban systems), respectively.

\subsubsection{Statistical models}

Mean/maximum ST and mean $E_{r}$ values at different temporal resolutions (monthly scale and over the entire period time, i.e. nine months) were correlated with land use shares (\%), stream azimuth, and lake distances, to determine the role of landscape variables in modifying ST.

Another objective was to compare the efficiency of purely statistical and hybrid models in quantifying air-stream temperature relationship at finer time-scales. For this, linear/logistic regression models and the air2stream model were tested using daily air temperature and ST data. The model performances were compared by calculating the Root Mean Square Error (RMSE, ${ }^{\circ} \mathrm{C}$ ) and the Nash-Sutcliffe Efficiency index (NSE; Nash and Sutcliffe, 1970). The RMSE provides an estimate of the accuracy of predicted stream temperatures and NSE provides a normalized measure of model performance by weighting the average variability of model residuals with respect to the variability of the target series (Piccolroaz et al., 2016).

\section{Results}

\subsection{Temporal variability and spatial heterogeneity in stream temperature}

The daily mean ST of the River Spree (all sites) ranged between $0{ }^{\circ} \mathrm{C}$ (February) and $27.8^{\circ} \mathrm{C}$ (July). Spatially, differences in several metrics of ST, such as mean ST over the entire study period (overall mean), daily mean ST, sub-daily ST values, and timings of maximum ST, were observed among sites (Table 2; Fig. 2). The largest spatial difference in daily mean ST $\left(5.1^{\circ} \mathrm{C}\right)$ was observed between sites S2 $\left(10.8{ }^{\circ} \mathrm{C}\right)$ and S20 $\left(15.9^{\circ} \mathrm{C}\right)$ [observed on 5 May 2014]. The highest sub-daily ST were attained at lake outlets (S6, S10) and downstream of urban areas (S14, S18, S19, S20). At most of these sites (namely S6, S14, S19, S20), ST peaked earlier in the season, compared to all other sites (Table 2, 'Time at maximum ST'), i.e., 0.05-2.14 days earlier at sites S6, S14 and S19, and 0.01 to 2.15 days earlier at S20.

Spatial differences in ST were primarily observed at locations upstream and downstream of urban areas and of lakes. The difference in 


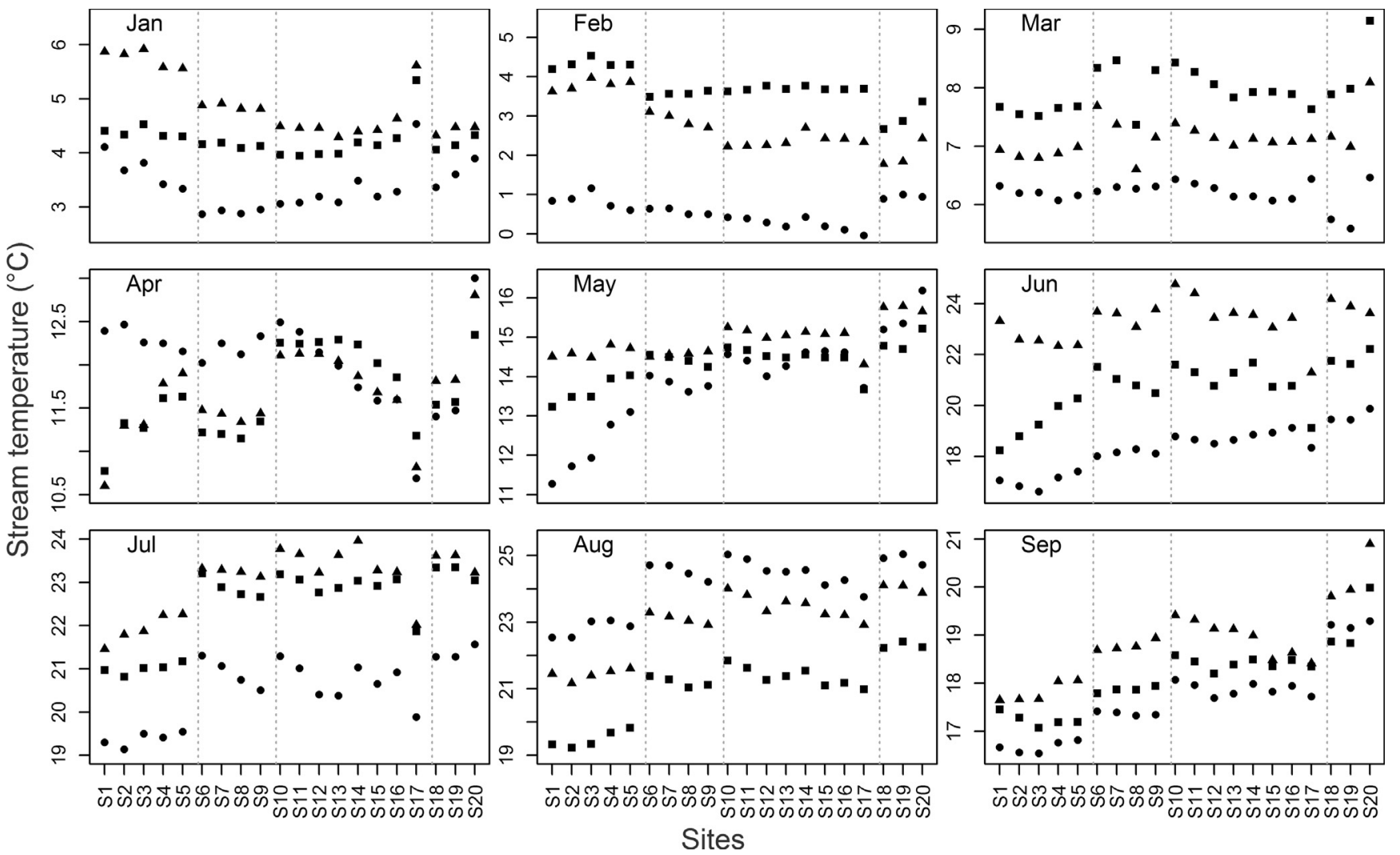

Fig. 2. Thermal heterogeneity in the study reach shown by plotting daily means for three random days in a month [4th (circular points), 10th (triangular points) and 15th (squared points)], plotted for the 20 sites on River Spree for all months during the study period. Vertical dashed lines indicate the section-wise subdivision (Table 2).

daily mean ST downstream and upstream of urban areas (S14-S13, S20-S16) ranged between -0.8 and $2.1^{\circ} \mathrm{C}$ in summer and between -0.6 and $2.9^{\circ} \mathrm{C}$ in winter. The difference in daily mean ST of lake inflow and outflow sites (S5-S6; S9-S10; S16-S18) ranged between $1.3^{\circ} \mathrm{C}$ and $2.9{ }^{\circ} \mathrm{C}$ during summer (warmer outflow) and $-0.6^{\circ} \mathrm{C}$ and $-1.4^{\circ} \mathrm{C}$ during winter (colder outflow). As the heat from the lake dissipated along the reach, a downstream cooling trend in ST was observed below lakes in summer (e.g., S6, S10). However, no distinct changes were observed at the sites downstream of lake Müggelsee (i.e., from S18 which is situated at the lake outlet), which were all located in an urban area.

Empirically, the $195 \mathrm{~km}$ long river course could be subdivided into four thermal sections (Fig. 1). These sections were created by thermal discontinuities induced by three major lakes and a major urban area located along the river (Table 2). Section I is defined by sites S1-S5 and situated within a mixture of forested and agricultural land with urban areas interspersed in some regions. Section II contains sites S6-S9 and is mainly situated in agricultural areas. Sites S10-S17 constitute section III, which is situated in semi-forested/agricultural areas. Section IV is situated within the city of Berlin and contains sites S18-S20. Within section III, site S17 differed from all other sites, with cooler temperatures between April and July and warmer temperatures during January compared to the other sites in this section.

At a coarse spatial scale, the ST increased downstream in summer, with each section being warmer than the adjacent upstream section. During winter, the ST exhibited a downstream decrease, with minor differences between sections II and III (Fig. 2).

Spatial differences in maximum and minimum ST exhibited a similar pattern as observed for mean ST. The daily temperature range (difference between diel maximum and minimum ST), however, portrayed a different pattern as observed for mean ST (Fig. S3). Along the river course, maximum values of daily ST range were observed primarily at sites S6, S8, S14, and S15.

3.2. Quantification of landscape contributions to thermal heterogeneity, dominant thermal processes and the air-water temperature relationship

\subsubsection{Heat-budget approach: Spatial variation in $\mathrm{E}_{\mathrm{r}}$}

The residual energy flux term $E_{r}$ denotes heat flux contributions via different land use types and lakes outflows (non-atmospheric sources) within a reach. The mean $E_{r}$ over the study period was positive (and highest) for sites at lake outlets (namely S6, S10, S18) and/or within urban areas (namely, S14, S18, S19 and S20). Hence, lakes and urban areas function as heat sources (Fig. 3a). Positive daily $E_{r}$ values were detected for $52-63 \%$ of the study period (mostly during summer months, June to September) for sites S6, S10, S14, S18, S19, S20 (Fig. 3b and c). Negative daily $E_{r}$ values, implying cooling effects, were often associated with the presence of forested areas and only occurred in absence of lakes (e.g. sites S2, S4, S7, S11-S13, S15).

\subsubsection{Lagrangian model: Identifying dominant thermal processes within the study reach}

To demonstrate how the upstream conditions impacted ST behaviour at a site, ST was simulated via the LAGR (Eq. (4)) and the LOC (Eq. (5)) models for Section II (Fig. 4). As expected, comparisons between simulated and observed ST at S9 (downstream site in Section II) showed that the LAGR model (RMSE $=0.5^{\circ} \mathrm{C}$ ) performed better than the LOC model (RMSE $=1.9^{\circ} \mathrm{C}$ ), because advective terms were neglected in the latter model. The mean values of the simulated ST from the LAGR model and the LOC model were $23.5^{\circ} \mathrm{C}$ (standard error, S.E. $=0.023^{\circ} \mathrm{C}$ ) and $22.0^{\circ} \mathrm{C}\left(\right.$ S.E. $=0.021{ }^{\circ} \mathrm{C}$ ), respectively; and the observed mean ST was $23.7^{\circ} \mathrm{C}\left(\right.$ S.E. $=0.021{ }^{\circ} \mathrm{C}$ ). Furthermore, these simulations demonstrated that approximately $70 \%$ of total solar radiation was incident on the river section (Fig. 4a), as the simulated and 
a)

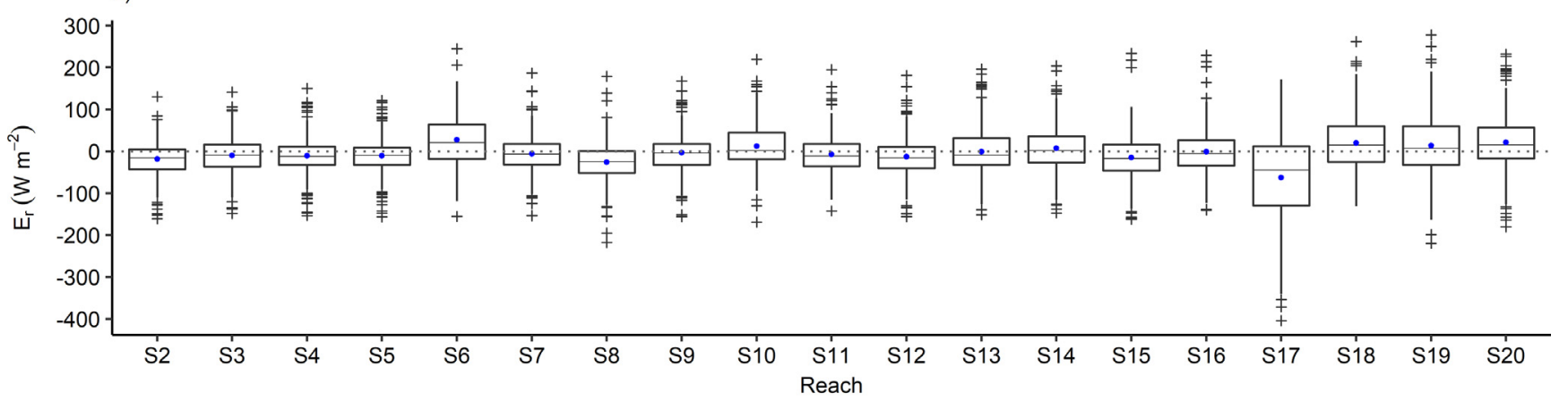

b)

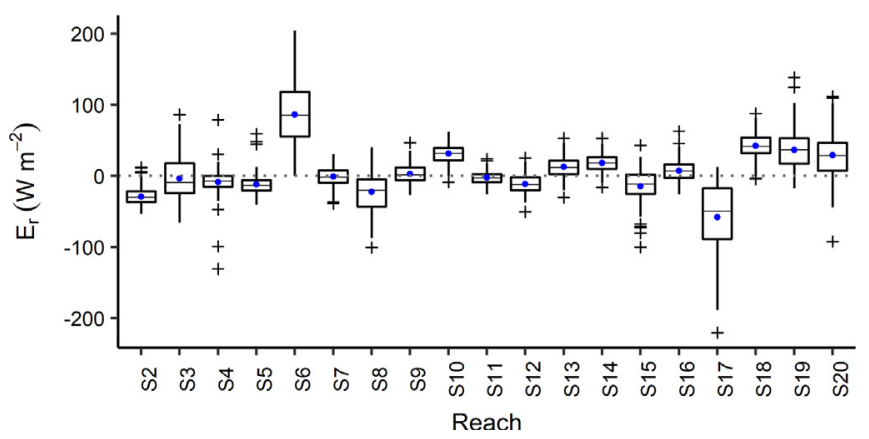

c)

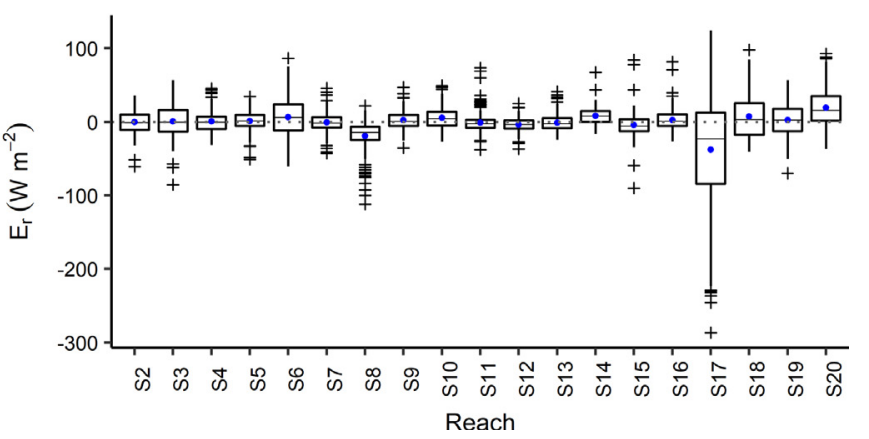

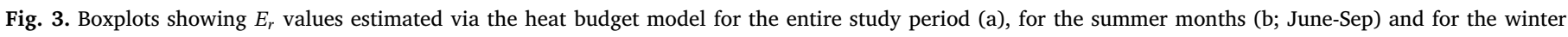

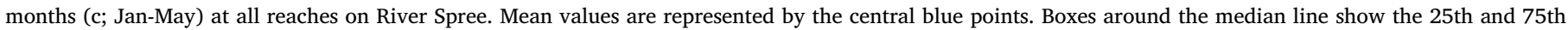
percentiles with whiskers representing the 5th and 95th percentiles and each cross representing the upper and lower outliers.

observed values fit best at this value.

The second step was to ascertain the influence of riparian shading in moderating ST. Complete riparian shading (solar radiation value set to 0) under the LAGR model scheme resulted in lowering of ST, although not as much as under the LOC model scheme (Fig. 4b). Under the LAGR model scheme, the absolute differences between STs (at $15 \mathrm{~min}$ time steps) simulated at $\mathrm{S} 9$ under the complete shading scenario and current shading conditions ranged from 0.2 to $3.1^{\circ} \mathrm{C}$ (mean $=1.5^{\circ} \mathrm{C}$; RMSE $=1.6^{\circ} \mathrm{C}$ ). However, the maximum STs from both conditions differed by only $1.2^{\circ} \mathrm{C}$ (complete shading $=25.3^{\circ} \mathrm{C}$, current $=26.5^{\circ} \mathrm{C}$ ). On the other hand, applying the LOC model scheme, the absolute differences between the STs simulated under the two conditions ranged from 0 to $8.8^{\circ} \mathrm{C}$ (mean $=5.1{ }^{\circ} \mathrm{C}$; RMSE $=5.4^{\circ} \mathrm{C}$ ), while the maximum simulated ST under the complete shading scenario was $1.4^{\circ} \mathrm{C}$ lower than that under the current condition. These results showed that complete riparian shading was less effective in lowering ST in reaches dominated by advected heat rather than atmospheric fluxes.

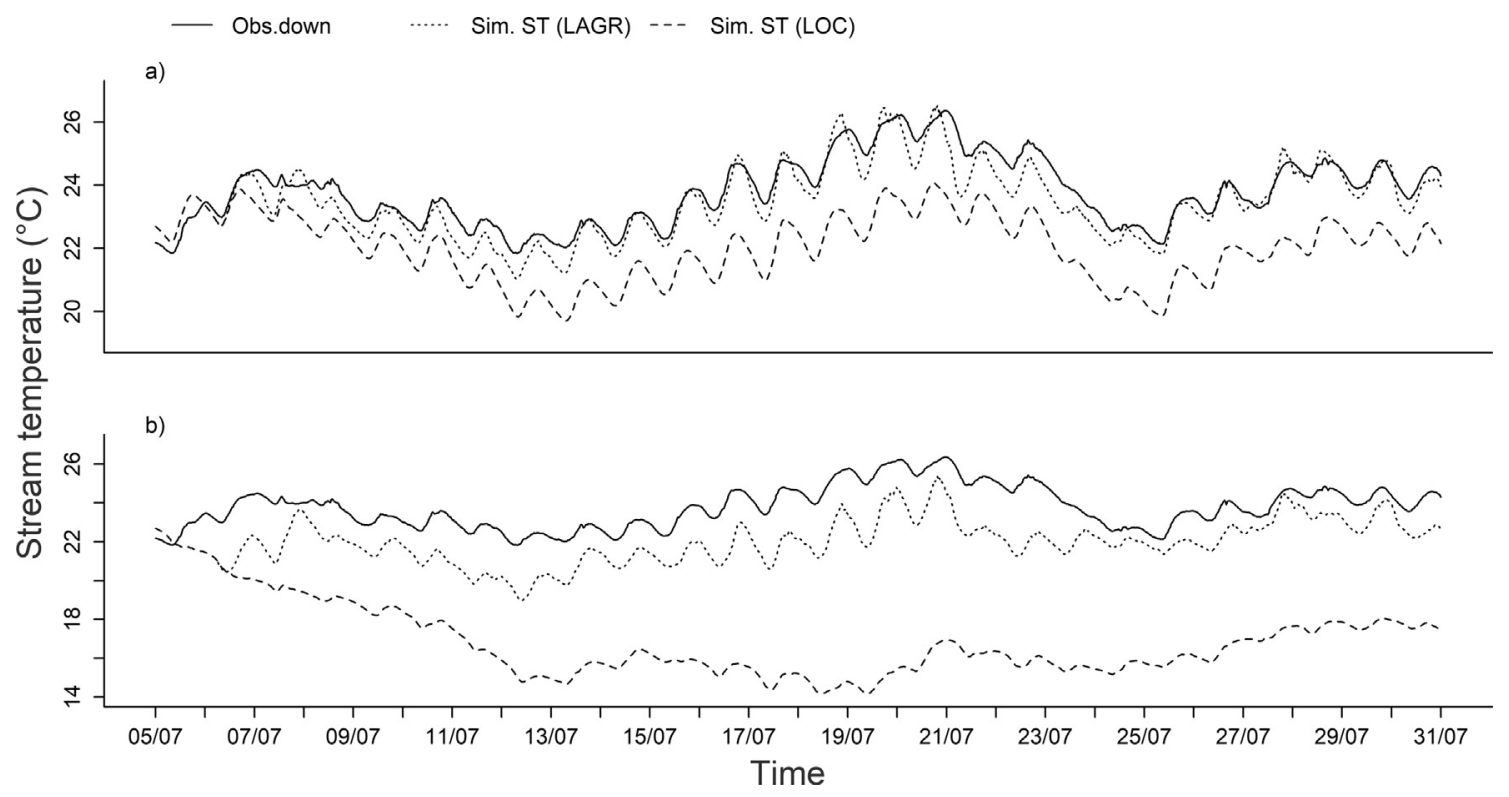

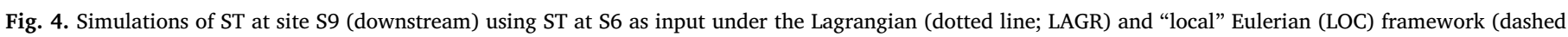

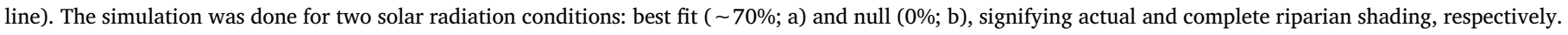
The solid line denotes the observed ST values at site S9. 


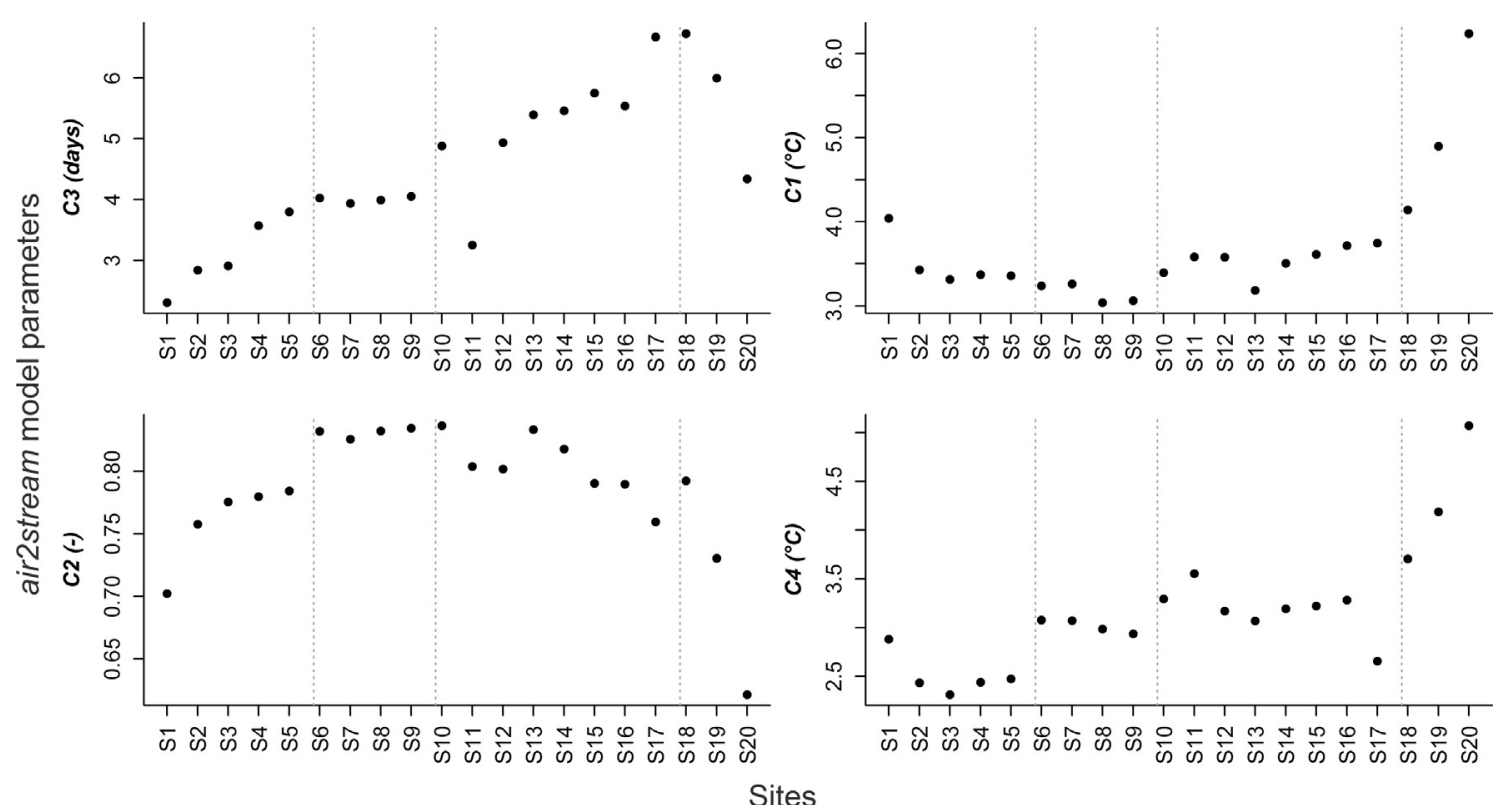

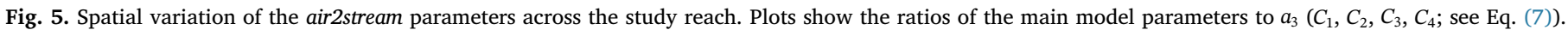
Vertical dashed lines indicate the section-wise subdivision of the river course.

\subsubsection{Semi-empirical modelling: Spatial variation in model parameters}

The calibrated parameters of the air2stream model were analysed to identify heat sources and sinks governing the thermal response of the river. Despite the relatively long adaptation time $C_{3}$ ( $>1$ day: 2.3 [S1] to 6.7 days [S18], see Fig. 5), the ratios defined in Eq. (7) provided a meaningful interpretation of the dominant processes.

Parameter $C_{3}$, the time required for adaptation of ST to local conditions, increased in the downstream direction along the river course till S18 (Fig. 5). This is likely due to increasing water volume (thermal inertia) and/or cumulative energy advected from upstream reaches, which can delay water temperature responses to local conditions (Johnson et al., 2014). Parameter $C_{4}$, indicating the contribution of landscape variables to ST dynamics, varied between 2.3 and $5{ }^{\circ} \mathrm{C}$. The largest values were estimated for the monitoring sites located in the most downstream urban section of the river (S18-S20, Fig. 5). Parameter $C_{1}$, which incorporates the annual constant flux in the model, varied between 3 and $6.2^{\circ} \mathrm{C}$, and the highest values were again estimated for the three downstream sites (S18-S20, Fig. 5). Parameter $C_{2}$, the coefficient associated with air temperature, varied less than the other parameters $(0.6-0.8)$, and the lowest value was attained at site S20 (Fig. 5), where the heat fluxes that were not explicitly resolved (proportional to $C_{4}$ ) became dominant.

\subsubsection{Statistical approach: Correlations with landscape variables}

Stream temperature: Significant correlations between ST metrics and landscape variables were detected at various time scales (over the entire study period, at monthly and at daily scales [see Table S3]). Urban area shares in $100-1000 \mathrm{~m}$ buffers and in $50-1000 \mathrm{~m}$ buffers were significantly and positively correlated with the mean ST over the study period (Table 3) and the monthly mean STs (during May-September, Table 4), respectively. Forest area shares in $\leq 100 \mathrm{~m}$ buffers had significant negative correlations with the overall mean ST and the monthly mean STs (Tables 3 and 4).

Mean ST was negatively correlated with lake distance during spring and summer months (April-September) and over the entire period, but was positively correlated in January and February (Tables 3 and 4). No significant correlations between stream azimuth and ST were detected at the monthly scale and over the entire study period.

Residual heat flux $E_{r}$ : Urban area shares (all buffer widths) had significant positive correlations with the mean $E_{r}$ over the entire study
Table 3

Pearson's coefficients for significant correlations of mean stream temperature (for the entire period), mean $E_{r}$ (for the entire period) with landscape variables (LV). "Not significant" ( $p>0.05$ ) correlations are not shown and are denoted by NS. $p$-values for significant correlations are provided within the brackets.

\begin{tabular}{lll}
\hline LV & ST & $E_{r}$ \\
\hline Forest area_in 50 m buffer (F_50) & $-0.52(0.02)$ & NS \\
F_100 & $-0.49(0.03)$ & NS \\
F_500 & NS & NS \\
F_1000 & NS & NS \\
Agricultural area_in 50 m buffer (A_50) & NS & NS \\
A_100 & NS & NS \\
A_500 & NS & NS \\
A_1000 & NS & NS \\
Urban area_in 50 m buffer (U_50) & NS & $0.47(0.04)$ \\
U_100 & $0.49(0.03)$ & $0.49(0.04)$ \\
U_500 & $0.52(0.02)$ & $0.50(0.03)$ \\
U_1000 & $0.47(0.04)$ & $0.47(0.04)$ \\
Lake distance & $-0.74(<0.01)$ & NS \\
Stream azimuth & NS & NS \\
\hline
\end{tabular}

period (Table 3) and the monthly mean $E_{r}$ (August and September, Table 5), identifying them as heat sources. Forest shares in 500-1000 m buffers were negatively correlated with the monthly mean $E_{r}$, signifying that they reduced heat inputs within the river at a monthly scale (Table 5).

Monthly mean $E_{r}$ was negatively correlated with lake distance in summer months (June to September), while it was positively correlated in February (Table 5). No significant correlations between $E_{r}$ and stream azimuth were found.

\subsection{Air temperature-stream temperature relationship: semi-empirical versus statistical models}

In general, the performances of the air-stream temperature regression models at a daily scale were not satisfactory. Linear regression models showed the poorest performance (RMSE $=2.4-3.3^{\circ} \mathrm{C}$, NSE $=0.82-0.87$ ), with performance decreasing in the downstream direction (Fig. 6). Logistic models performed better than the linear models, given the non-linear (s-shaped) relationship between air temperature and ST. The performance of logistic regression models also 
Table 4

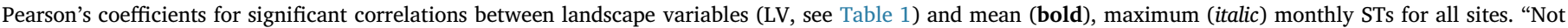
significant" $(p>0.05)$ correlations are not shown and are denoted by NS. $p$-values for significant correlations are provided within the brackets.

\begin{tabular}{|c|c|c|c|c|c|c|c|c|c|}
\hline LV/Month & Jan & Feb & Mar & Apr & May & Jun & Jul & Aug & Sep \\
\hline F_50 & NS & NS & NS & NS & NS & $-0.49(0.03)$ & $\begin{array}{l}-0.52(0.02) \\
-0.46(0.047)\end{array}$ & $\begin{array}{l}-0.60(0.01) \\
-0.54(0.02)\end{array}$ & $\begin{array}{l}-0.55(0.01) \\
-0.62(<0.01)\end{array}$ \\
\hline F_100 & NS & NS & NS & NS & NS & NS & $-0.48(0.04)$ & $\begin{array}{l}-0.58(0.01) \\
-0.49(0.03)\end{array}$ & $\begin{array}{l}-0.55(0.01) \\
-0.62(0.01)\end{array}$ \\
\hline F_500 & NS & NS & NS & NS & NS & NS & NS & NS & NS \\
\hline F_1000 & NS & NS & NS & NS & NS & NS & NS & NS & NS \\
\hline A_50 & NS & $0.54(0.02)$ & NS & NS & NS & NS & NS & NS & NS \\
\hline A_100 & NS & $0.56(0.01)$ & NS & NS & NS & NS & NS & NS & NS \\
\hline A_500 & NS & $0.61(0.01)$ & NS & NS & $-0.48(0.04)$ & NS & NS & NS & $-0.51(0.03)$ \\
\hline A_1000 & NS & $\begin{array}{l}0.53(0.02) \\
0.56(0.01)\end{array}$ & NS & NS & $-0.50(0.03)$ & NS & NS & $-0.53(0.02)$ & $-0.59(0.01)$ \\
\hline U_50 & NS & $-0.58(0.01)$ & NS & NS & NS & NS & NS & $0.47(0.04)$ & $0.58(0.01)$ \\
\hline U_100 & NS & $-0.64(<0.01)$ & NS & NS & $0.47(0.04)$ & NS & NS & $0.52(0.02)$ & $0.63(0.004)$ \\
\hline U_500 & NS & $-0.64(<0.01)$ & NS & NS & $0.49(0.03)$ & NS & NS & $0.56(0.01)$ & $0.66(0.002)$ \\
\hline U_1000 & NS & $-0.64(<0.01)$ & NS & NS & NS & NS & NS & $0.51(0.02)$ & $0.62(0.004)$ \\
\hline Lake distance & $\begin{array}{l}0.67(<0.01) \\
0.77(<0.01)\end{array}$ & $0.60(<0.01)$ & NS & $\begin{array}{l}-0.50(0.03) \\
-0.66(<0.01)\end{array}$ & $\begin{array}{l}-0.69(<0.01) \\
-0.70(<0.01)\end{array}$ & $\begin{array}{l}-0.80(<0.01) \\
-0.78(<0.01)\end{array}$ & $\begin{array}{l}-0.83(<0.01) \\
-0.84(<0.01)\end{array}$ & $\begin{array}{l}-0.71(<0.01) \\
-0.85(<0.01)\end{array}$ & $\begin{array}{l}-0.62(<0.01) \\
-0.81(<0.01)\end{array}$ \\
\hline Stream azimuth & NS & NS & NS & NS & NS & NS & NS & NS & NS \\
\hline
\end{tabular}

Table 5

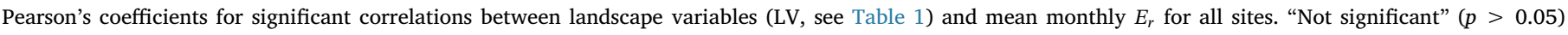
correlations are not shown and are denoted by NS. $p$-values for significant correlations are provided within the brackets.

\begin{tabular}{|c|c|c|c|c|c|c|c|c|c|}
\hline LV/Month & Jan & Feb & Mar & Apr & May & Jun & Jul & Aug & Sep \\
\hline F_50 & NS & NS & NS & NS & NS & NS & NS & NS & NS \\
\hline F_100 & NS & NS & NS & NS & NS & NS & NS & NS & NS \\
\hline F_500 & NS & NS & NS & NS & NS & NS & NS & $-0.53(0.02)$ & $-0.51(0.02)$ \\
\hline F_1000 & NS & NS & NS & NS & NS & NS & NS & $-0.51(0.02)$ & $-0.51(0.03)$ \\
\hline A_50 & NS & NS & NS & NS & NS & NS & NS & NS & NS \\
\hline A_100 & NS & NS & NS & NS & NS & NS & NS & NS & NS \\
\hline A_500 & NS & NS & NS & NS & NS & NS & NS & NS & NS \\
\hline A_1000 & NS & NS & NS & NS & NS & NS & NS & NS & NS \\
\hline U_50 & NS & NS & NS & NS & NS & NS & NS & $0.53(0.02)$ & $0.50(0.03)$ \\
\hline U_100 & NS & NS & NS & NS & NS & NS & NS & $0.56(0.01)$ & $0.55(0.02)$ \\
\hline U_500 & NS & NS & NS & NS & NS & NS & NS & $0.61(0.01)$ & $0.60(0.01)$ \\
\hline U_1000 & NS & NS & NS & NS & NS & NS & NS & $0.57(0.01)$ & $0.55(0.01)$ \\
\hline Lake distance & NS & $0.54(0.02)$ & NS & NS & NS & $-0.47(0.04)$ & $-0.49(0.03)$ & $-0.57(0.01)$ & $-0.46(0.05)$ \\
\hline Stream azimuth & NS & NS & NS & NS & NS & NS & NS & NS & NS \\
\hline
\end{tabular}
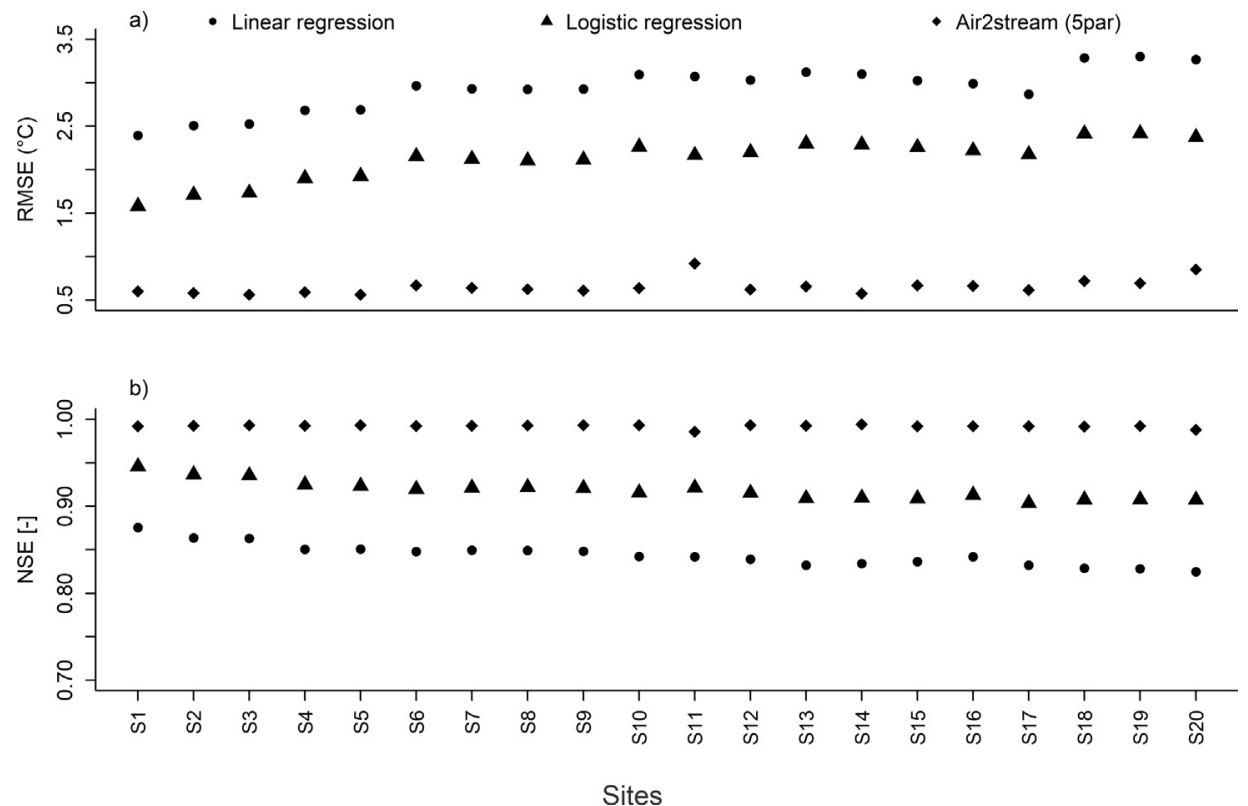

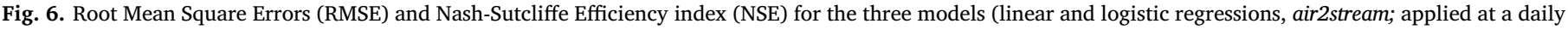
scale) for all sites on River Spree. 
decreased downstream (RMSE $=1.6-2.4^{\circ} \mathrm{C}$, NSE $\left.=0.91-0.94\right)$. Compared to the regression models, the performance of the air2stream model was significantly better $\left(\mathrm{RMSE}=0.6-0.9^{\circ} \mathrm{C}\right.$, NSE $=0.98-0.99$, Fig. 6; Kruskal-Wallis test, $\mathrm{P}<0.001)$.

\section{Discussion}

\subsection{Thermal heterogeneity along the river course and responsible factors}

Along the $195 \mathrm{~km}$ river course, the mean and maximum ST differed among sites at daily and monthly scales as well as over the entire study period. As a general trend, the river sections warmed in the downstream direction in summer and cooled in the same direction in winter. Conceptually, rivers are expected to warm asymptotically in the downstream direction towards an equilibrium temperature (Caissie, 2006; Fullerton et al., 2015). This downstream increase in ST is mostly because of net cumulative gains in radiant energy in the absence of major tributaries and groundwater flow (Johnson et al., 2014). However, a recent study in North America observed that rivers exhibited different patterns (linear, parabolic, uniform, complex) in downstream river warming (Fullerton et al., 2015). In the case of River Spree, we hypothesize that the presence of a large reservoir (Spremberg reservoir, Fig. 1) above the studied river course provided a water temperature that was different (lower in warmer and higher in colder months) than the equilibrium water temperature, hence resulting in the asymptotic trend. Furthermore, the addition of heat advected from the upstream reaches due to the presence of urban areas or lakes could also be a plausible reason for the observed trend. Simulations from the Lagrangian model showed that the effect of advected heat, especially along sections below lakes, persisted over distances of up to $20 \mathrm{~km}$, which was the dominant process determining the mean ST.

Based on the observed spatial pattern in daily mean ST, four thermally homogenous river sections were identified in summer months. The results from different modelling approaches (positive residual heat flux term, $E_{r}$, and high values of parameter $C_{4}$ ) suggested that the presence of urban areas and lakes were the primary causes of ST differences between the four river sections. Similar results were highlighted by Booth et al. (2014), who identified upstream lakes, local urban cover and watershed geology as important ST controls in several lowland North American streams.

Differences of up to $3{ }^{\circ} \mathrm{C}$ were observed between sites situated before and after urban areas. Cities tend to create urban heat islands, as air and ground surface temperature within cities tend to be higher than in rural surroundings (Pickett et al., 2001). Consequently, water temperature in rivers flowing through heat islands tend to be higher as well (also due to additional heat sources, e.g., from sewage inputs) than those in rural and forested areas (Somers et al., 2013). Several studies have reported similar or much larger differences (up to $8^{\circ} \mathrm{C}$ ) between urban and nonurban areas (Pluhowski, 1970; Somers et al., 2013; Booth et al., 2014).

Pre- and post-lake STs differed by -1 to $3^{\circ} \mathrm{C}$ in this study, an observation also made in other studies (Pedersen and Sand-Jensen, 2007; Booth et al., 2014). In river sections downstream of lakes, a progressive cooling trend was observed in summer. The diminishing influence of warm initial ST provided by shallow lakes at outlets (in summer) and increasing dominance of other local factors with increasing distance from lakes can create downstream cooling conditions over considerable distances (Mellina et al., 2002; Moore et al., 2005; Booth et al., 2014). Lake outflows flowing through urban areas, however, showed slight warming or little change downstream (in summer), possibly due to additional heat inputs from urban areas or a higher equilibrium temperature in that region, thereby, preventing heat loss.

The variations in the values of ST sensitivity to air temperature (described by the parameter $C_{2}$; Fig. 5) also demonstrated the influence of landscape variables. Both local controls, such as site characteristics, and non-local controls, such as cumulative influence of the upstream network, quantify the magnitude of sensitivity. In general, ST sensitivity to air temperature increases with increasing river order (i.e. increasing downstream) as a function of accumulated heat via exchange at the air-water interface throughout the stream network (Kelleher et al., 2012). However, this trend was seen only in the first $40 \mathrm{~km}$ of the studied river course, after which the sensitivity either remained constant or decreased, again implying the role of other sources. The sensitivity was the highest at lake outlets (S6, S10). Most lakes located in the study area are small, shallow and wide (Table S4), possibly exchanging energy rapidly with ambient air temperature and solar radiation at the surface. Also, water temperatures at lake outlets are probably more influenced by water temperatures at the lakeshore, which are typically shallower. ST sensitivity to air temperature at site S18, which is also below a lake, was not as high as other lake-influenced sites. This is probably because the lake before S18 (lake Müggelsee) is deeper (max. depth $=8 \mathrm{~m}$ ) than the other lakes (max. depth $=3 \mathrm{~m}$ ), thereby supplying cooler and warmer outflows in summer and winter months, respectively.

\subsection{Potential influence of discharge on thermal heterogeneity}

Discharge is an important variable influencing the thermal regime of rivers. The sensitivity of ST to atmospheric influences is determined by thermal capacity and travel time, which change with flow depth and hence, the ST sensitivity tends to decrease/increase with increasing/ decreasing discharge (Pedersen and Sand-Jensen, 2007).

The discharge of River Spree typically ranges from 5 to $20 \mathrm{~m}^{3} / \mathrm{s}$ (Nützmann et al., 2014; Table S1) and is potentially affected by tributaries, groundwater inflow and has been altered for urban and agricultural use. The spatial and temporal variation in discharge could, therefore, influence thermal heterogeneity along the river course. Although the contribution of discharge was not explicitly considered in the study, thermal heterogeneity via discharge variations due to tributary influence and human use were implicitly considered in the semiempirical and HB modelling approaches by means of the residual (unresolved) heat flux terms. However, heat inputs via tributaries usually become more significant during low flow conditions, which were not recorded during the study.

Preliminary analyses showed that the influence of discharge on ST at a daily scale was minor to moderate $\left(\mathrm{R}^{2}=0.03\right.$ to 0.55$)$, with minor influence $\left(\mathrm{R}^{2}<0.5\right)$ on ST on most sites (see Table S5). However, it is possible that the discharge influence on ST is more prevalent at shorter time scales (e.g., hourly). Alternatively, poor correlations between discharge and ST could be an artefact of distance between the ST sites and discharge measurement locations, as for most of the ST sites the discharge data used was not from the same location. Discharge and water temperature data for tributaries would be required to ascertain whether heat inputs or losses from the tributaries could play a significant role in the observed thermal heterogeneity.

Heat inputs or losses via groundwater to the thermal budget of a river may be important too, particularly for small rivers such as headwaters (Kelleher et al., 2012; Johnson et al., 2014). Significant groundwater contributions usually result in higher ST in winter and lower ST in summer. In the case of the River Spree, contribution of groundwater to thermal heterogeneity was considered negligible because of the similar conductivity across most sites. However, groundwater contributions seemed particularly significant at site S17, which had cooler ST in warmer months and warmer ST in cooler months than nearby sites. Additionally, one of the highest adaptation time (parameter $C_{3}$, Fig. 5) and low thermal sensitivity to air temperature (parameter $C_{2}$, Fig. 5) were also observed at this site. These observations suggest a possible significant groundwater inflow at S17, possibly due to close contact of the logger with the river bed, as high groundwater inputs may result in weaker correlations with air temperature (Kelleher et al., 2012; Johnson et al., 2014). As for S9 and S11, despite having the lowest water conductivity of all sites, the ST at these sites did not show any unusual behaviour, probably due to the dominance of advected 
heat from nearby lakes. However, unusually small lag value at S11 as compared to other sites in the section (parameter $C_{3}$, Fig. 5) might be attributable to dominance of other local factors such as agricultural canal inflows, which have faster adaptation times.

\subsection{Influence zones of landscape variables}

Urban area shares (all buffer widths, across various time scales) and lake distances (primarily at monthly scale) were consistently related to the spatial pattern in ST and $E_{r}$. These results signify that higher ST and heat inputs occur with increasing urban area and proximity to lakes, hence, supporting the model results.

Forest area had a significant but an inconspicuous role in reducing heat inputs and moderating ST along the river course. However, the results concerning the effective width of forest buffer were not consistent. Forest area shares within $50 \mathrm{~m}$ buffer and $500-1000 \mathrm{~m}$ buffers had a significant influence on ST and $E_{r}$, respectively. Hrachowitz et al. (2010) also investigated the effectiveness of riparian buffers, demonstrating that site-specific characteristics such as discharge and morphology modify the influence of riparian buffer width on ST. Moreover, the moderating influence of forested areas on ST is less pronounced in larger rivers, where increasing channel width prevents complete river shading and reduces the impact of riparian forest microclimates on the energy budget (Hannah et al., 2008; Hrachowitz et al. 2010). However, expansive riparian forests might reduce ST along larger rivers via reducing surface and near-surface soil temperatures in summer and, thereby, affecting the temperature of surface runoff - in addition to lowering ambient air temperature and wind speed (Moore et al., 2005; Hannah et al., 2008). Hence, contiguous riparian forest buffers wider than $1000 \mathrm{~m}$ might be more effective for the lowland River Spree, although this assumption requires final validation.

Regarding the efficacy of the longitudinal extent of riparian buffers, previous studies have demonstrated the efficacy of riparian shading in reducing mean and maximum ST (Moore et al., 2005; Malcolm et al., 2008; Roth et al., 2010; Imholt et al., 2013; Garner et al., 2014; Dugdale et al., 2018). For instance, Roth et al. (2010) simulated the ST response for a $1.3 \mathrm{~km}$ upland reach in Switzerland and found that the maximum ST increased by $0.7^{\circ} \mathrm{C}$ in a cleared vegetation scenario, while it decreased by $1.2^{\circ} \mathrm{C}$ when mature riparian forest spanned the entire reach. Garner et al. (2014) also observed a maximum instantaneous difference of $2.5^{\circ} \mathrm{C}$ in a $1 \mathrm{~km}$ upland reach in U.K. transitioning from open moorland to a semi-natural forest land use. A combination of reduced rates of heating and advection of cooler water from the upstream moorland catchment were proposed as the underlying processes of this change. On the other hand, our study showed that even complete shading required a comparatively long distance $(20 \mathrm{~km})$ to create an average change of $1.5^{\circ} \mathrm{C}$ in sub-daily ST in lake-influenced lowland sections. This suggests that in sections downstream of shallow lakes, heat advection is the dominant thermal process in summer (heat source) and moderating ST in such sections would require measures other than riparian buffer plantation in addition to riparian shading.

\subsection{Air-stream temperature relationship: Beyond regression models}

The weak performance of the air-water temperature regression models, especially of linear regressions, at the daily scale raises a question regarding their widespread applicability. In general, air and stream temperature correlations are typically weak at a daily time scale (Mohseni and Stefan, 1999; Erickson and Stefan, 2000). However, applications of regression models at weekly scales yielded similar poor performances (Morrill et al., 2005; Arismendi et al., 2014). Unaccounted first or second order autocorrelation in regression models applied at short-time scales weakens their predictive ability, leading to under- or overestimation of values. Autocorrelations are seldom acknowledged by studies, and accounting for them could improve the performance of these models (Benyahya et al., 2007; Johnson et al.,
2014). Semi-empirical models, such as air2stream applied in this study, are more efficient as they perform with much better accuracy with the same amount of input data as required by regression models. In addition, they simultaneously preserve the physical basis provided by deterministic models and, hence, are not affected by unaccounted autocorrelation (air2stream can be interpreted as a first order autocorrelation model given the presence of the time derivative). In this study, the semi-empirical model was able to capture and highlight the important reach-scale ST controls within the study area. Further applications of this model at a larger spatial scale have revealed similar results (Piccolroaz et al., 2016). As emphasized by Arismendi et al., (2014), while the application of simple regression approaches can be attractive, there is a need to move beyond these regression approaches (Toffolon and Piccolroaz, 2015), especially for relatively fine time-scale applications (Piccolroaz et al., 2016). Modelling approaches, such as demonstrated in this study, provide a wide scope to do so and encourage development of similar or better tools for characterising and predicting ST.

\section{Conclusion}

Despite the fact that the effect of landscape variables on thermal heterogeneity among river systems has been extensively studied, quantifying and understanding within-system thermal heterogeneity remains an ongoing challenge (Webb et al., 2008; Fullerton et al., 2015). This study investigated thermal heterogeneity along the $195 \mathrm{~km}$ course of a sixth-order lowland river in NE Germany (River Spree), and the role of landscape variables such as land use and the presence of lakes in defining this heterogeneity. We observed significant thermal discontinuities in summer and identified four distinct thermal sections at daily, monthly and seasonal scales. Consistent results were obtained from the application of heat budget modelling, semi-empirical modelling, and statistical analysis to quantify thermal heterogeneity, and its underlying drivers. We found that the specific location of urban areas (cities) and lakes, rather than the spatial arrangement of various land use types (i.e. forest, agriculture, urban), induced thermal discontinuities, thereby enhancing the heterogeneity along the river course, particularly during summer. The effect of urban areas and lakes was similar across various time scales. The effects of the urban microclimate on ST increased with urban area. Hence, investigating the effects of the so-called 'urban stream syndrome' on thermal regimes and patterns in rivers (Somers et al., 2013) is imperative, given the cumulative impacts of ongoing climate change, population growth, urbanisation and anthropogenic activities on river systems. Additionally, nearnatural upstream river sections should be preserved to mitigate present and future effects of climate change on the thermal regime of entire river courses. Although planting or preserving riparian buffers is among the most popular management measures to reduce nutrient emissions and to maintain natural thermal regimes, their effectiveness in regulating water temperature depends on landscape and morphological properties of the river. In the case of lowland River Spree, measures such as plantation or maintenance of contiguous riparian areas would likely be more effective in regulating ST when implemented along with other management options, such as improving the groundwater table recharge, managing the temperature of urban discharges or creating shaded artificial ponds. Furthermore, application of alternative models to statistical regression models at finer time scales is encouraged for modelling ST and forecasting its future trends, both of which are important tools for effective river management.

\section{Acknowledgements}

R. Arora was funded by the SMART Joint Doctoral Programme (Science for the MAnagement of Rivers and their Tidal systems; http:// web.unitn.it/en/riverscience), which is financed by the Erasmus Mundus programme of the European Union. This work is also part of 
the MARS project (Managing Aquatic ecosystems and water Resources under multiple Stress), funded under the 7th EU Framework Programme (Contract No.: 603378; http://www.mars-project.eu). We thank Judith Mahnkopf and Matthias Gadegast for their help during site visits, and Elisa Calamita and Sebastiano Piccolroaz for their support in the simulations using the air2stream model. The source code of this model can be freely downloaded from https://github.com/ marcotoffolon/air2stream. The comments by three anonymous reviewers, which helped to improve the manuscript, are highly appreciated.

\section{Appendix I: Heat fluxes}

The net thermal energy $\left(E_{a t m}, \mathrm{~W} \mathrm{~m}^{-2}\right)$ exchanged through the surface of a water body can be expressed as:

$E_{\text {atm }}=E_{s}+E_{h}-E_{b}-E_{e}-E_{c}$

where $E_{s}$ is the shortwave radiation absorbed, $E_{h}$ the atmospheric longwave back radiation, $E_{b}$ the back radiation from water surface, $E_{e}$ the heat loss due to evaporation, $E_{c}$ the net heat flux due to sensible heat transfer.

The following relationships were derived from Martin and McCutcheon (1998), where not otherwise specified. Typical values adopted in the analysis are reported within parentheses.

$E_{S}$ was calculated as (Imboden and Wüest, 1995):

$E_{s}=(1-r) H_{s}\left(1-0.65 C^{2}\right)$

where $=r 0.2, H_{s}$ is clear sky solar radiation $\left(\mathrm{W} \mathrm{m}^{-2}\right)$, and $C$ is cloud fraction $(-)$.

$E_{h}$ was calculated as:

$E_{h}=\alpha 0.97 \sigma\left(T_{a}+273.16\right)^{6}(1+0.17 C)$

where $\alpha$ is a proportionality constant $\left(0.937 \times 10^{-5}\right)$, $\sigma$ is the Stefan-Boltzmann constant $\left(5.67 \times 10^{-8} \mathrm{~W} \mathrm{~m}^{-2} \mathrm{~K}^{-4}\right)$ and $T_{a}$ is the air temperature $\left({ }^{\circ} \mathrm{C}\right)$.

$E_{b}$ was calculated as:

$E_{b}=0.97 \sigma\left(T_{w}+273.16\right)^{4}$

where $T_{w}$ is the water temperature $\left({ }^{\circ} \mathrm{C}\right)$.

$E_{e}$ was calculated as:

$E_{e}=\rho L_{w} E$

where

$E=(a+b W)\left(e_{s}-e_{a}\right) E_{s}=(1-r) H_{s}\left(1-0.65 C^{2}\right)$

$e_{s}=2.171 \times 10^{8} e^{\left.\left(-4157 / T_{d}+239.09\right)\right)\left(-/ T_{d}+239.09\right)}$

$e_{a}=2.171 \times 10^{8} e^{\left(-4157 / T_{d}+239.09\right)}$

$T_{d}=T_{a}-(100-r h) / 5$

Here, $a\left(1 \times 10^{-10} \mathrm{mbar}^{-1} \mathrm{~m} \mathrm{~s}^{-1}\right)$ and $b\left(1 \times 10^{-9} \mathrm{mbar}^{-1}\right)$ are wind coefficients, $W$ is the wind speed ( $\left.\mathrm{m} \mathrm{s}^{-1}\right), E$ is the rate of evaporation $\left(\mathrm{m} \mathrm{s}^{-1}\right), e_{s}$ is the saturated vapour pressure at the water surface temperature (mbar), $e_{a}$ is the vapour pressure at the air temperature (mbar), $L_{w}$ is the latent heat of evaporation $\left(2.4 \times 10^{6} \mathrm{~J} \mathrm{~kg}^{-1}\right), \rho$ is the density of water $\left(997 \mathrm{~kg} \mathrm{~m}^{-3}\right), T_{d}$ is the dew point temperature $\left({ }^{\circ} \mathrm{C}\right)$, and $r h$ is the relative humidity (\%).

$E_{c}$ can be calculated as:

$E_{c}=\rho L_{w}(a+b W) C_{b}\left(P_{a} / P\right)\left(T_{w}-T_{a}\right)$

where $C_{b}$ is the Bowen's ratio $\left(0.61 \mathrm{mbar}^{\circ} \mathrm{C}^{-1}\right), P_{a}$ is the atmospheric pressure (mbar), and $P$ is the reference pressure at mean sea level (1005 mbar).

\section{Appendix B. Supplementary data}

Supplementary data associated with this article can be found, in the online version, at https://doi.org/10.1016/j.jhydrol.2018.05.066.

\section{References}

Arbeitsgemeinschaft der Vermessungs-verwaltungen der Länder der Bundesrepublik Deutschland: Erläuterungen zum ATKIS-Objektartenkatalog der Arbeitsgemeinschaft der Vermessungsverwaltungen der Länder der Bundesrepublik Deutschland. Available at: http://www.adv-online.de/Geotopography/ATKIS/.

Arismendi, I., Safeeq, M., Dunham, J.B., Johnson, S.L., 2014. Can air temperature be used to project influences of climate change on stream temperature? Environ. Res. Lett. 9 (8), 084015.

Arora, R., Tockner, K., Venohr, M., 2016. Changing river temperatures in Northern Germany: trends and drivers of change. Hydrol. Process. 30 (17), 3084-3096.

Arscott, D.B., Tockner, K., Ward, J.V., 2001. Thermal heterogeneity along a braided floodplain river (Tagliamento River, northeastern Italy). Can. J. Fish Aquat. Sci. 58 (12), 2359-2373.

Benyahya, L., Caissie, D., St-Hilaire, A., Ouarda, T.B., Bobée, B., 2007. A review of statistical water temperature models. Can. Water Resour. J. 32 (3), 179-192.
Booth, D.B., Kraseski, K.A., Rhett Jackson, C., 2014. Local-scale and watershed-scale determinants of summertime urban stream temperatures. Hydrol. Process. 28 (4), 2427-2438.

Broadmeadow, S.B., Jones, J.G., Langford, T.E.L., Shaw, P.J., Nisbet, T.R., 2011. The influence of riparian shade on lowland stream water temperatures in southern England and their viability for brown trout. River Res. Apps. 27, 226-237.

Brown, L.E., Hannah, D.M., 2008. Spatial heterogeneity of water temperature across an alpine river basin. Hydrol. Process 22 (7), 954-967.

Cai, H., Piccolroaz, S., Huang, J., Liu, Z., Liu, F., Toffolon, M., 2018. Quantifying the impact of the Three Gorges Dam on the thermal dynamics of the Yangtze River. Environ. Res. Lett. https://doi.org/10.1088/1748-9326/aab9e0.

Caissie, D., 2006. The thermal regime of rivers: a review. Freshwater Biol. 51, 1389-1406.

Chang, H., Psaris, M., 2013. Local landscape predictors of maximum stream temperature and thermal sensitivity in the Columbia River Basin, USA. Sci. Total. Environ. 461, 587-600.

Dugdale, S.J., Bergeron, N.E., St-Hilaire, A., 2015. Spatial distribution of thermal refuges analyzed in relation to riverscape hydromorphology using airborne thermal infrared 
imagery. Remote Sens. Environ. 160, 43-55.

Dugdale, S.J., Malcolm, I.A., Kantola, K., Hannah, D.M., 2018. Stream temperature under contrasting riparian forest cover: understanding thermal dynamics and heat exchange processes. Sci. Total Environ. 610-611, 1375-1389.

Ellis, L.E., Jones, N.E., 2013. Longitudinal trends in regulated rivers: a review and synthesis within the context of the serial discontinuity concept. Environ. Rev. 21 (3), 136-148. https://doi.org/10.1139/er-2012-0064.

Environmental Protection Agency (EPA) U.S.. 2008. Chapter 1: Urban heat island basics. In: Reducing Urban Heat Islands: Compendium of Strategies. Washington, DC: U.S. Environmental Protection Agency. https://www.epa.gov/heat-islands/reducingurban-heat-islands-compendium-strategies.

Erickson, T.R., Stefan, H.G., 2000. Linear air/water temperature correlations for streams during open water periods. J. hydrol. Eng. 5 (3), 317-321.

Friberg, N., Christensen, J.B., Olafsson, J.S., Gislason, G.M., Larsen, S.E., Lauridsen, T.L., 2009. Relationship between structure and function in streams contrasting in temperature: possible impacts of climate change on running water ecosystems. Freshwater Biol. 54, 2051-2206.

Fullerton, A.H., Torgersen, C.E., Lawler, J.J., Faux, R.N., Steel, E.A., Beechie, T.J., Ebersole, J.L., Leibowitz, S.G., 2015. Rethinking the longitudinal stream temperature paradigm: region-wide comparison of thermal infrared imagery reveals unexpected complexity of river temperatures. Hydrol. Process. 29 (22), 4719-4737.

Fullerton, A.H., Torgersen, C.E., Lawler, J.J., Steel, E.A., Ebersole, J.L., Lee, S.Y., 2018. Longitudinal thermal heterogeneity in rivers and refugia for coldwater species: effects of scale and climate change. Aquat Sci. 80, 3.

Garner, G., Malcolm, I.A., Sadler, J.P., Hannah, D.M., 2014. What causes cooling water temperature gradients in a forested stream reach? Hydrol. Earth Syst. Sci. 18, 5361-5376.

Hannah, D.M., Garner, G., 2015. River water temperature in the United Kingdom: changes over the 20th century and possible changes over the 21st century. Prog. Phys. Geog. 39 (1), 68-92.

Hannah, D.M., Malcolm, I.A., Soulsby, C., Youngson, A.F., 2008. A comparison of forest and moorland stream microclimate, heat exchanges and thermal dynamics. Hydrol. Process. 22 (7), 919-940.

Hebert, C., Caissie, D., Satish, M.G., El-Jabi, N., 2011. Study of stream temperature dynamics and corresponding heat fluxes within Miramichi River catchments (New Brunswick, Canada). Hydrol. Process. 25 (15), 2439-2455.

Hrachowitz, M., Soulsby, C., Imholt, C., Malcolm, I.A., Tetzlaff, D., 2010. Thermal regimes in a large upland salmon river: a simple model to identify the influence of landscape controls and climate change on maximum temperatures. Hydrol. Process. 24 (23), 3374-3391.

Imboden, D.M., Wüest, A., 1995. Mixing mechanisms in lakes. In: Lerman, A., Imboden, D., Gat, J. (Eds.), Physics and chemistry of lakes. Springer, Berlin Heidelberg, pp. 83-138.

Imholt, C., Soulsby, C., Malcolm, I.A., Hrachowitz, M., Gibbins, C.N., Langan, S., Tetzlaff, D., 2013. Influence of scale on thermal characteristics in a large montane river basin. River Res. Apps. 29 (1), 403-419.

Isaak, D.J., Wollrab, S., Horan, D., Chandler, G., 2012. Climate change effects on stream and river temperatures across the northwest U.S. from 1980-2009 and implications for salmonid fishes. Climatic Change 113, 499-524.

Isaak, D.J., Rieman, B.E., 2013. Stream isotherm shifts from climate change and implications for distributions of ectothermic organisms. Glob. Change Biol. 19 (3), $742-751$.

Johnson, M.F., Wilby, R.L., 2015. Seeing the landscape for the trees: Metrics to guide riparian shademanagement in river catchments. Water Resour. Res. 51, 446.

Johnson, M.F., Wilby, R.L., Toone, J.A., 2014. Inferring air-water temperature relationships from river and catchment properties. Hydrol. Process. 28, 2912-2928.

Kaushal, S.S., Likens, G.E., Jaworski, N.A., Pace, M.L., Ashley, M., Seekell, D., Belt, K.T., Secor, D.H., Wingate, R.L., Sides, A.M., 2010. Rising stream and river temperatures in the United States. Front. Ecol. Environ. 8 (9), 461-466.

Kelleher, C., Wagener, T., Gooseff, M., McGlynn, B., McGuire, K., Marshall, L., 2012. Investigating controls on the thermal sensitivity of Pennsylvania streams. Hydrol. Process. 26 (5), 771-785.

Kozerski, H.P., Köhler, J., Schellenberger, G. 1991. Transport of particulate nutrients and pollutants in the lowland River Spree. In: Sediment and steam water quality in a changing environment: trends and explanation. Proceedings of a symposium held during the XXth General Assembly of the International Union of Geodesy and Geophysics, Vienna, Austria (pp. 11-24).

Leach, J.A., Moore, R.D., 2011. Stream temperature dynamics in two hydrogeomorphically distinct reaches. Hydrol. Process. 25, 679-690.

LeBlanc, R.T., Brown, R.D., FitzGibbon, J.E., 1997. Modeling the effects of land use change on the water temperature in unregulated urban streams. J. Environ. Manage. 49 (4), 445-469.

Li, H., Reynolds, J., 1995. On definition and quantification of heterogeneity. Oikos 73 (2), 280-284.

Malcolm, I.A., Soulsby, C., Hannah, D.M., Bacon, P.J., Youngson, A.F., Tetzlaff, D., 2008. The influence of riparian woodland on stream temperatures: implications for the performance of juvenile salmonids. Hydrol. Process. 22, 968-979.

Markovic, D., Scharfenberger, U., Schmutz, S., Pletterbauer, F., Wolter, C., 2013 Variability and alterations of water temperatures across the Elbe and Danube River Basins. Climatic Change 119 (2), 375-389.

Martin, J.L., McCutcheon, S.C., 1998. Chapter 8: Stratification and heat transfer in lakes and reservoirs. Hydrodynamics and Transport for Water Quality Modeling. CRC Press, Chicago.

Mayer, T.D., 2012. Controls of summer stream temperature in the Pacific Northwest. J Hydrol 475, 323-335.

Mellina, E., Moore, R.D., Hinch, S.G., Macdonald, J.S., Pearson, G., 2002. Stream temperature responses to clearcut logging in British Columbia: the moderating influences of groundwater and headwater lakes. Can. J. Fish Aquat. Sci. 59, 1886-1900.

Mohseni, O., Stefan, H.G., 1999. Stream temperature/air temperature relationship: a physical interpretation. J. Hydrol. 218 (3-4), 128-141.

Monk, W.A., Wilbur, N.M., Curry, R.A., Gagnon, R., Faux, R.N., 2013. Linking landscape variables to coldwater refugia in rivers. J. Environ. Manage. 118, 170-176.

Moore, R.D., Spittlehouse, D.L., Story, A., 2005. Riparian microclimate and stream temperature response to forest harvesting: a review. J. Am. Water Resour. Assoc. 41 (4), 813-834.

Morrill, J.C., Bales, R.C., Conklin, M.H., 2005. Estimating stream temperature from air temperature: implications for future water quality. J. Environ. Eng. 131 (1), 139-146.

Nash, J.E., Sutcliffe, J.V., 1970. River flow forecasting through conceptual models 1. A discussion of principles. J. Hydrol. 10, 282-290.

Nelson, K.C., Palmer, M.A., 2007. Stream temperature surges under urbanization. J. Am. Water Resour. Assoc. 43 (2), 440-452.

Nützmann, G., Levers, C., Lewandowski, J., 2014. Coupled groundwater flow and heat transport simulation for estimating transient aquifer-stream exchange at the lowland River Spree (Germany). Hydrol. Process. 28 (13), 4078-4090.

Pedersen, N.L., Sand-Jensen, K., 2007. Temperature in lowland Danish streams: contemporary patterns, empirical models and future scenarios. Hydrol. Process. 21, 348-358.

Piccolroaz, S., Toffolon, M., Majone, B., 2013. A simple lumped model to convert air temperature into surface water temperature in lakes. Hydrol. Earth Syst. Sci. 17, 3323-3338.

Piccolroaz, S., Toffolon, M., Majone, B., 2015. The role of stratification on lakes' thermal response: the case of Lake Superior. Water Resour. Res. 51, 7878-7894.

Piccolroaz, S., Calamita, E., Majone, B., Gallice, A., Siviglia, A., Toffolon, M., 2016. Prediction of river water temperature: a comparison between a new family of hybrid models and statistical approaches. Hydrol. Process. 30 (21), 3901-3917.

Piccolroaz, S., Healey, N.C., Lenters, J.D., Schladow, S.G., Hook, S.J., Sahoo, G.B., Toffolon, M., 2018. On the predictability of lake surface temperature using air temperature in a changing climate: a case study for Lake Tahoe (U.S.A.). Limnol. Oceanogr. 63 (1), 243-261.

Pickett, S.T., Cadenasso, M.L., Grove, J.M., Nilon, C.H., Pouyat, R.V., Zipperer, W.C., Costanza, R., 2001. Urban ecological systems: linking terrestrial ecological, physical, and socioeconomic components of metropolitan areas. Ann. Rev. Eco. Syst. 32 (1), $127-157$.

Pluhowski, E.J. 1970. Urbanization and its effect on the temperature of streams on Long Island, New York. US Geological Survey Professional Paper 627-D.

Poole, G.C., Berman, C.H., 2001. An ecological perspective on in-stream temperature: natural heat dynamics and mechanisms of human-caused thermal degradation. Environ. Manage. 27, 787-802.

Pusch, M., Behrendt, H., Gancarczyk, A., Kronvang, B., Sandin, L., Stendera, S., Wolter, C., Andersen, H.E., Fischer, H., Hoffmann, C.C., Nowacki, F. 2009. Chapter 14: Rivers of the central European highlands and plains. In Tockner K, Uehlinger U, Robinson CT (Eds.) Rivers of Europe. Academic Press, ISBN-13:978-0-12-369449-2.

Rice, K.C., Jastram, J.D., 2015. Rising air and stream-water temperatures in Chesapeake Bay region, USA. Climatic Change 128, 127-138.

Roth, T.R., Westhoff, M.C., Huwald, H., Huff, J.A., Rubin, J.F., Barrenetxea, G., Vetterli, G., Parriaux, A., Selker, J.S., Parlange, M.B., 2010. Stream temperature response to three riparian planting scenarios by use of a distributed temperature validated model. Environ. Sci. Technol. 44, 2072-2078.

Somers, K.A., Bernhardt, E.S., Grace, J.B., Hassett, B.A., Sudduth, E.B., Wang, S., Urban, D.L., 2013. Streams in the urban heat island: spatial and temporal variability in temperature. Freshw Sci. 32 (1), 309-326.

Sun, N., Yearsley, J., Voisin, N., Lettenmaier, D.P., 2015. A spatially distributed model for the assessment of land use impacts on stream temperature in small urban watersheds. Hydrol. Process. 29 (10), 2331-2345.

Toffolon, M., Piccolroaz, S., 2015. A hybrid model for river water temperature as a function of air temperature and discharge. Environ. Res. Lett. 10 (11), 114011.

Toffolon, M., Piccolroaz, S., Majone, B., Soja, A.M., Peeters, F., Schmid, M., Wüiest, A. 2014. Prediction of surface temperature in lakes with different morphology using air temperature. Limnol. Oceanogr. 59 (6), 2182-2202.

van Vliet, M.T., Franssen, W.H., Yearsley, J.R., Ludwig, F., Haddeland, I., Lettenmaier, D.P., Kabat, P., 2013. Global river discharge and water temperature under climate change. Global Environ. Change 23 (2), 450-464.

van Vliet, M.T.H., Ludwig, F., Zwolsman, J.J.G., Weedon, G.P., Kabat, P., 2011. Global river temperatures and sensitivity to atmospheric warming and changes in river flow. Water Resour. Res. 47, W02544.

Vannote, R.L., Minshall, G.W., Cummins, K.W., Sedell, J.R., Cushing, C.E., 1980. The river continuum concept. Can. J. Fish Aquat. Sci. 37 (1), 130-137.

Webb, B.W., Hannah, D.M., Moore, R.D., Brown, L.E., Nobilis, F., 2008. Recent advances in stream and river temperature research. Hydrol. Process. 22, 902-918.

Webb, B.W., 1996. Trends in stream and river temperature. Hydrol. Process. 10 (1), 205-226. 